\title{
Influence of stone column installation on settlement reduction
}

\author{
by \\ Jorge Castro $\left({ }^{1}\right)(*)$, Minna Karstunen $\left({ }^{2}\right)$ and Nallathamby Sivasithamparam $\left({ }^{3}\right)$ \\ E-mail: $\left({ }^{1}\right)$ castrogj@unican.es $\quad\left(^{2}\right)$ minna.karstunen@chalmers.se \\ $\left(^{3}\right)$ nallathamby.siva@ngi.no \\ $\left({ }^{1}\right)$ Lecturer, Department of Ground Engineering and Materials Science, University of \\ Cantabria, Santander, Spain \\ $\left({ }^{2}\right)$ Professor, Department of Civil and Environmental Engineering, Chalmers University of \\ Technology, Gothenburg, Sweden \& Docent, Aalto University, Espoo, Finland \\ $\left({ }^{3}\right)$ Computational Geomechanics Division, Norwegian Geotechnical Institute, Oslo, \\ Norway \& Plaxis B.V., Delft, The Netherlands \\ (*) Corresponding author: \\ Group of Geotechnical Engineering \\ Department of Ground Engineering and Materials Science \\ University of Cantabria \\ Avda. de Los Castros, s/n \\ 39005 Santander, Spain \\ Tel.: +34 942201813 \\ Fax: +34 942201821 \\ e-mail: castrogj@unican.es
}

Date: December 2013

Number of words: 6,000

Number of tables: 4

Number of figures: 16 


\begin{abstract}
The paper presents numerical simulations investigating the settlement reduction caused by stone columns in a natural soft clay. The focus is on the influence of the soft soil alteration caused by column installation. A uniform mesh of end-bearing columns under a distributed load was considered. Therefore, the columns were modelled using the "unit cell" concept, i.e. only one column and the corresponding surrounding soil in axial symmetry. The properties of the soft clay correspond to Bothkennar clay, which is modelled using S-CLAY1 and S-CLAY1S, which are Cam clay type models that account for anisotropy and destructuration. The Modified Cam clay model is also used for comparison. Column installation was modelled independently to avoid mesh distortions, and soft soil alteration was directly considered in the initial input values. The results show that the changes in the stress field, such as the increase of radial stresses and mean stresses and the loss of overconsolidation, are beneficial for high loads and closely spaced columns but, on the contrary, may be negative for low loads, widely spaced columns and overconsolidated soils. Moreover, whilst the rotation of the soil fabric reduces the settlement, in contrast the soil destructuration during column installation reduces the improvement.
\end{abstract}

Keywords: stone columns; installation; settlement reduction; numerical modelling; anisotropy, destructuration. 


\section{Introduction}

Stone columns are one of the most common ground improvement techniques to improve soft soil deposits. They reduce the total and the differential settlements, accelerate consolidation, improve the bearing capacity and the slope stability and reduce the liquefaction potential. The improvement is achieved through the inclusion of gravel or crushed stone, which has a higher stiffness, strength and permeability than the natural soft soil. In addition, column installation also modifies the properties of the surrounding soil. However, design of stone columns does not usually consider those installation effects and is usually based on their performance as rigid inclusions [1-3]. In this paper, the term 'installation effects' refers to the changes in the state of soil due to column installation. Some authors [4] account for certain changes in the stress state due to installation by assuming a higher value of the coefficient of earth pressure at rest than that for the natural soil. The paper discusses the influence of the installation effects on the settlement reduction, which is nowadays one of the major concerns in an accurate design of stone columns [5].

Stone columns are installed using a deep vibrator, either electric or hydraulic, similar to those used for vibrocompaction or vibroflotation. However, the alteration caused by the vibrator is completely different in each ground improvement technique because of the different soil characteristics. In vibrocompaction, the vibrator is used in granular soils, and the vibration compacts the surrounding soil. The soil densification is the most important effect of vibrocompaction, and has been mainly analysed using field measurements [6,7], as it is difficult to model the process numerically [8]. In contrast, stone columns are typically used in soft cohesive soils, as these cannot be compacted. The density of clay increases only after consolidation by the application of monotonic, 
long-term loads. Therefore, the installation effects of stone columns are not usually considered and the main effect is assumed to be the cavity expansion induced by the vibrating poker. There is also a range of soils that fall in between the two extremes discussed above, in which densification is still possible, but additional granular material is needed to ensure an effective improvement, e.g. to avoid liquefaction [9]. In this paper only a purely cohesive soft soil is considered.

Experimental studies have shown some of the effects of column installation, e.g. the increase of pore pressures and horizontal stresses, and the remoulding of the surrounding soil has been measured in the field [10-14]. There have also been attempts to investigate these effects through physical modelling of the process by means of centrifuge testing $[15,16]$, but the soils used are reconstituted and hence not fully representative of natural clays.

Modelling the problem theoretically is complex, and although the cavity expansion is a well-studied problem (e.g. $[17,18])$, there are few numerical analyses of the installation effects of stone columns $[19,20]$. The authors have recently studied this numerically using advance soil models to reproduce the behaviour of natural structured soft soils $[21]$.

Beyond the changes in the state of soil due to column installation, the knowledge of the influence that those changes have on the soil improvement is very limited. Schweiger [22] found that, if those changes are considered, the settlement of a circular footing was reduced but only for high load levels. The improvement is caused by the increase of mean stress in the clay, which enables the soil to carry more load and in turn provides a 
better lateral support for the columns. Column installation was modelled imposing a volumetric strain field, which is similar to input post-installation values of the soil density and the lateral earth pressure. However, this approach needs of approximate estimations of the volume change. Later, Kirsch [19] simulated the settlement reduction caused by installation effects of a group of floating columns in a sandy silt. He distinguished between individual installation effects, which were modelled applying a small cavity expansion (2-8\%), and a global installation effect in an enhanced zone around the group of columns with a higher stiffness (around twice the initial one). Those installation effects give a further reduction of the settlement of $40 \%$ and $5-25 \%$, respectively. In the work above, the installation effects were somehow back-calculated from field measurements.

To clarify the influence that the changes in the state of soil due to column installation have on the settlement reduction caused by the columns on soft cohesive soils, the authors carried out numerical simulations using two advanced constitutive models, namely S-CLAY1 [23] and S-CLAY1S [24], which have been especially developed to represent natural structured soft soils, a common type of soils to be treated with stone columns. The Modified Cam clay model (MCC) [25] has also been used for comparison. The paper presents the "unit cell" models used to study several column spacings and embankment heights, in which a curve fitting of the initial stresses and state variables is used to account for the installation effects. The settlement reduction achieved for the different cases is analysed. The comparison of the settlement improvement with and without installation effects demonstrates the influence of the changes in the stresses and soil structure, both fabric and interparticle bonding. The main positive and negative changes in the soil state due to column installation are 
highlighted. Depending on the analysed case, the effects of column installation either improve or reduce the settlement reduction of the stone column foundation.

\section{Numerical model}

The finite element code Plaxis v9 [26] was used to develop a numerical model of a reference problem that could help to understand the influence of the changes in the state of soil due to column installation. A uniform mesh of end-bearing columns under a distributed load was considered. Therefore, the columns were modelled using the "unit cell" concept, i.e. only one column and the corresponding surrounding soil in axial

symmetry (Figure 1). As all the columns are simultaneously loaded, they will respond in virtually the same fashion, which justifies symmetry conditions. The inner boundary of the "unit cell" is the axis of symmetry and a smooth contact is assumed at the bottom. Consequently, rigid, frictionless and shear free boundaries are used except in the upper boundary, where the embankment is located.

In order to consider a realistic situation, properties of Bothkennar clay were used for the soft soil. Stone columns have been applied in Bothkennar clay $[11,27]$ and similar Carse clays [5]. The Bothkennar soft clay test site has been the subject of a number of comprehensive studies [28]. The soil at Bothkennar consists of a firm to stiff silty clay crust about $1.0 \mathrm{~m}$ thick, which is underlain by about $19 \mathrm{~m}$ of soft clay. However, in the simulations the columns were assumed to reach a rigid layer at $10 \mathrm{~m}$ depth to avoid very long or floating columns. The ground water level is $1.0 \mathrm{~m}$ below the ground surface. Typically to a structured soil the in situ water content is close to the liquid limit. 
The behaviour of Bothkennar clay was modelled using the advanced constitutive models S-CLAY1 and S-CLAY1S. MCC was also used for comparison purposes. SCLAY1 is a Cam clay type of model with an inclined yield surface to model inherent anisotropy, and a rotational component of hardening to model the development or erasure of fabric anisotropy during plastic straining. The state parameter $\alpha$ defines the inclination of the yield surface in a $p^{\prime}-q$ diagram (Figure 2). The scalar value of $\alpha$ is defined in a simplified triaxial stress space and is useful for common cross-anisotropic soils, but its vector definition $\left\{\alpha_{i}\right\}$ is necessary for more general cases as those present in this paper. The soil constants $\mu$ and $\beta$ are part of the rotational hardening law. $\mu$ controls the rate at which the inclination of the yield surface tends towards its current target value, which depends on the current stress path. $\beta$ defines the relative effectiveness of plastic shear (deviatoric) and volumetric strains in changing the anisotropy. The initial inclination of the yield surface $\left(\alpha_{0}\right)$ may be directly correlated with $K_{0}$ for a normally consolidated state, and similarly a theoretical link exists between $\beta$ value and normally consolidated $K_{0}$. A test involving significant rotation of the yield surface, e.g. isotropic consolidation or undrained shearing in triaxial extension, could be used to calibrate $\mu$, but in practice empirical correlations with $\lambda$ are used [23].

The S-CLAY1S model accounts, additionally, for interparticle bonding and degradation of bonds, using an intrinsic yield surface and a hardening law describing destructuration as a function of plastic straining. The bonding parameter, $\chi$, relates the sizes of the natural and intrinsic yield surfaces $\left(\chi=p_{m}^{\prime} / p_{m i}^{\prime}-1\right)$ (Figure 2). It may be related to the sensitivity of the soil, $\chi=S_{t}-1$. Parameters $a$ and $b$ relate to the third additional hardening law used in the model, which describes the degradation of bonding with plastic straining. Parameter $a$ controls the absolute rate of destructuration and parameter $b$ 
defines the relative effectiveness of plastic shear (deviatoric) and volumetric strains [24]. For this constitutive model the slope of the post yield compression line, $\lambda$, corresponds to an intrinsic value, $\lambda_{i}$, which can be obtained from oedometer tests on reconstituted samples. In contrast, for S-CLAY1, the value for $\lambda$ is determined from oedometer tests on intact soil samples.

The models have been implemented as User-defined soil models in Plaxis. An implementation that uses an automatic substepping in combination with a modified Newton-Raphson integration scheme [29] has been used instead of previous version of Euler backward scheme used in Castro and Karstunen [21].

The values for S-CLAY1S model parameters (soil constants) for Bothkennar clay are listed in Table 1 and are the same as those previously used by the authors in their study of the changes in the state of soil due to column installation [21]. S-CLAY1S model is formulated to be a hierarchical model, which reduces to S-CLAY1 by assuming $a=0$ and $\chi_{0}=0$, and using the apparent value of $\lambda$. It further reduces to MCC model by additionally assuming $\mu=0$ and $\alpha_{0}=0$. Note that the initial state variables correspond to in situ soil properties before column installation. As explained in a later section, they are altered to account for column installation (post-installation values).

An embankment of $5 \mathrm{~m}$, with the common properties listed in Table 2, was used to represent the distributed load. The height and stiffness of the embankment allow for a full arching of the load, which can be considered as rigid. That was expected beforehand but also confirmed by the results. Therefore, the most important property of the embankment is the applied vertical pressure $\left(p_{a}=\gamma_{e}^{\prime} H\right)$, where $\gamma_{e}^{\prime}$ is the effective unit 
weight of the embankment and $H$ is its height. $p_{a}$ is usually normalised by the initial vertical stresses $\left(\sum \gamma_{s}^{\prime} z\right)$ (e.g. [2]). $\gamma_{s}^{\prime}$ is the effective unit weight of each layer of natural soil and $z$ is the thickness of each layer over the depth considered. As a reference, its value at the mean depth is 2.5 .

Crushed stone (gravel) is used for column backfill and common properties were chosen for the numerical model (Table 2). The Young's modulus of the column $\left(E_{\mathrm{c}}=35 \mathrm{MPa}\right)$ was chosen based on a common modular ratio of around $E_{\mathrm{c}} / E_{\mathrm{s}}=60$. A linear elasticperfectly plastic soil model using the Mohr-Coulomb yield criterion was considered to be representative enough to reproduce the interaction between the embankment and the column.

Column spacing is usually defined by the area replacement ratio, $a_{r}$ (area of the column, $A_{c}$, divided by the area of the unit cell, $A_{l}$ ) or in terms of the radius or diameter ratio, $N=r_{l} / r_{c}=1 / \sqrt{ } a_{r}$. Three different values, namely $N=2,3$ and 5, were used as representative of the common range. The column diameter was $0.8 \mathrm{~m}$ but it does not have an especial significance as most of the results can be scaled for other column diameters. An example of the finite element mesh is shown in Figure 1. Mesh sensitivity analyses were performed to confirm the accuracy of the mesh, i.e. the use of a finer mesh gave slightly higher settlements but the differences were negligible.

\section{Reference case without installation effects}

The first step to study the influence of column installation on the soil improvement, especially on the settlement reduction, is to analyse the case without considering any 
changes in the state of the soil due to column installation. This reference case is also used as a benchmark to evaluate the performance of the advanced constitutive models in a boundary value problem for soft soil.

After generation of the initial stresses, without considering any installation effects for this reference case, the column was wished in place and the embankment was built. The results assuming the embankment construction in drained conditions were nearly the same as those of an undrained loading followed by a consolidation phase (Table 3 ). Therefore, in the following, drained loading was used to save computation time. The consolidation analysis was fully coupled, following Biot's theory [30]. Terzaghi's principle to divide total stresses into effective stresses and pore pressures and Darcy's law for the water flow were used. Soil grains were assumed as incompressible and a very high bulk modulus of the water was considered. Consolidation was computed using a fully implicit integration scheme [26]. For the consolidation analyses, the lateral and bottom boundaries were assumed as impervious. Only the soft soil was assumed as undrained, while the embankment and the column were assumed as fully drained. The horizontal and vertical hydraulic conductivities of Bothkennar clay were assumed as 1.4 and $0.7 \times 10^{-9} \mathrm{~m} / \mathrm{s}$, respectively [28]. Twice those values were used for the upper crust.

The settlement of the soft soil under the embankment load is plotted in Figure 3. This process corresponds to one dimensional compression. The small change of gradient of the settlement curve when the embankment height is around $1.4 \mathrm{~m}$ is caused by the slight overconsolidation of the soft soil $(O C R=1.5)$. MCC predicts slightly less settlement than S-CLAY1 because it overpredicts the horizontal stresses in a $K_{0}$-stress path. Consequently, the mean stress, $p^{\prime}$, is slightly higher, and so is the apparent bulk 
stiffness of the soil. In this case, $K_{0}=0.59$ for MCC, whist with S-CLAY1 type models realistic $K_{0}$-stress paths are predicted through inclusion of soil anisotropy, in this case $K_{0}=0.43$, which is the normally consolidated $(\mathrm{NC})$ value $\left(K_{0, N C}=1-\sin \phi\right)$. In the SCLAY1 type models, the yield surface is rotated to give the desired (realistic) $K_{0}$ value. In one dimensional compression, the incremental strain ratio is $\frac{d \varepsilon_{d}}{d \varepsilon_{v}}=\frac{2}{3}$, and, if the elastic strains are neglected, using the associated flow rule, $\frac{d \varepsilon_{d}^{p}}{d \varepsilon_{v}^{p}}=\frac{2(\eta-\alpha)}{M^{2}-\eta^{2}}$, the correct stress path is obtained as $\eta_{K 0}=3 \frac{1-K_{0}}{1+2 K_{0}}$.

When the embankment load becomes more significant, S-CLAY1S model predicts considerably less settlement, which is more realistic because the slope of the virgin compression line for MCC and S-CLAY1 $(\lambda=0.48)$ is constant, and was adjusted for lower stress levels when destructuration is important. For higher stress levels, that apparent $\lambda$ value is too high. On the contrary, in the S-CLAY1S model, the apparent slope of the virgin compression line reduces with loading due to destructuration (Figure $4)$.

When the soil is improved with columns, the settlement is reduced and closer column spacings reduce predicted settlement (Figure 5). Differences between soil models follow similar trends as for the case without columns. The improvement is usually evaluated using the settlement reduction factor (Figure 6), defined as the ratio between the final settlement with and without improvement, $\beta=s_{z} / s_{z 0}$, or its inverse the improvement factor, $n$. For very low loads, $\beta$ is constant and the same for the different soil models because the soil is overconsolidated and behaves elastically in both improved and unimproved cases. For slightly higher loads, the soil yields when it is not improved but 
stays overconsolidated for the improved case. Therefore, there is a minimum value for an embankment height of around $1 \mathrm{~m}$. If the columns are closely spaced, they support more load and plastic strains in the improved soil appear later. That is why for $N=2$ the minimum in $\beta$ is for a higher embankment load than for higher column spacings, because the soil improved with $N=2$ needs a higher load to reach the preconsolidation pressure. Once the soil is normally consolidated, the settlement reduction factor increases with the load level because of the column yielding. In general, MCC predicts the best improvement because it overpredicts horizontal stresses and then, the column is better confined. On the contrary, S-CLAY1S predicts the worst improvement because the interaction between soil and column causes further soil destructuration.

\section{Installation effects}

Changes in the state of soil due to column installation were studied by the authors in a previous paper [21], which forms the basis for the present analysis. Column installation was modelled numerically as an expansion of a cylindrical cavity and the changes on the surrounding soil were revealed. The installation process of only one column was analysed, hence no interaction effects between the installations of several columns were considered. Furthermore, the vibratory action of the probe was not modelled because it is expected to have only a small influence on this type of soft soils.

Now, the aim is to study how the effects of installation of stone column influence the settlement reduction. Modelling the loading process directly after column installation is not convenient because the mesh is very distorted and boundary conditions may not be appropriate. Therefore, it was considered appropriate to model the loading process 
independently. The changes in the state variables of Bothkennar clay after column installation were studied and curve fitted. Those post-installation values were input as initial values in the unit cell model (Figure 1). Numerical implementation of this procedure for initializing the stresses and state variables was required.

The embankment was assumed to be raised after full dissipation of the excess pore pressures generated during column construction, which is the desired situation and seems to be true in most cases $[13,14]$. Besides, the upper crust was considered not to be affected by column installation for the sake of simplicity.

\subsection{Stress field}

Horizontal stresses increase after column installation and, therefore, the changes in the stress field are usually considered through an increase in the lateral earth pressure coefficient, $K_{0}$. For example, Priebe [4] already assumed in his method a value of $K_{0}=1$, which is higher than the initial value at rest for most soils. Kirsch [19] presented field measurements of $K_{0}$ and showed that after column installation values between 1 and 1.7 times the initial one have been measured, depending on the distance to the column. Elshazly et al. [31,32] have numerically back-calculated, from field measurements of load-displacement curves, values of $K_{0}$ between 0.7 and 2.5, with average values around 1.3 .

Assuming an increase of the $K_{0}$ value is a useful approach for column design but it is just a simplification of the changes in the stress field during column installation. Figure 7 shows the results for the three soil models considered. The distance to the column axis is in logarithmic scale to amplify the zone of interest near the column. The vertical, 
radial and hoop (circumferential) stresses may be still considered as the principal stresses as the shear stresses are negligible. The stress changes are different at different depths but they are directly proportional to the undrained shear strength, $c_{u}$, and therefore, also to the depth and the initial vertical stress in this case, because the $O C R$ value is constant apart from the upper crust.

In the analyses performed, the yield surface is circular in the deviatoric plane (DruckerPrager). The analytical derivation of $c_{u}$ for the MCC can be found, for example, in Potts and Zdravkovic [33]. Following a similar procedure, the value of $c_{u}$ for the S-CLAY1 model is:

$$
\frac{c_{u}}{\sigma_{z 0}^{\prime}}=O C R \frac{M}{\sqrt{3}} \cos \theta \frac{1+2 K_{0}^{N C}}{3}\left[1+\frac{\left(M-\alpha_{C S}\right)^{2}}{M^{2}-\alpha_{C S}^{2}}\right]^{\frac{\kappa}{\lambda}-1}\left(1+B^{2}\right)\left[\frac{\left(1+2 K_{0}^{O C}\right)}{\left(1+2 K_{0}^{N C}\right) O C R\left(1+B^{2}\right)}\right]^{\frac{\kappa}{\lambda}}
$$

where

$B=\frac{3\left(1-K_{0}^{N C}\right)\left(1+2 K_{0}^{N C}\right)-\alpha_{0}}{\sqrt{M^{2}-\alpha_{0}^{2}}}$

$\alpha_{C S}=\frac{\sqrt{3 M}}{6 \cos \theta}$ is the scalar anisotropy parameter at critical state and $\theta$ is the Lode's angle $\left(\theta=-30^{\circ}\right.$ in triaxial compression and $\theta=0^{\circ}$ in plane strain conditions). In this case, failure is reached for conditions similar to plane strain during the expansion of the cavity. Therefore, $c_{u}$ is defined for plane strain conditions (e.g. [17]). The $c_{u}$ values for the MCC $(\alpha=0)$ are different and, although the differences are very small in this case $(0.538$ and $0.545 \sigma_{z 0}^{\prime}$ for MCC and S-CLAY1, respectively), the results (Figure 7) have been normalised by the initial vertical stress to avoid ambiguity on the value of $c_{u}$.

As expected, radial stresses increase near the column, but vertical and hoop stresses also change (Figure 7). Vertical stresses increase in the part nearest to the column, with the 
exception of S-CLAY1S, for which vertical stress decreases because of destructuration. Interestingly, the hoop stresses are quite different to radial stresses. Three different zones may be distinguished: (1) an elastic one (beyond 11.5-13.5 column radii depending on the soil model) where soil behaviour is always elastic and hoop stresses decrease, (2) an area that is plastic during undrained expansion of the cavity but is not after consolidation, where vertical stresses change only slightly and (3) points that are on the yield surface also after consolidation (closer than 4.5-6 column radii), where the initial yield surface is expanded. To clarify that, the stress paths of points in the different zones are plotted in Figure 8 for the MCC as an example. In Zone 3, there are points where the yield surface is significantly expanded (Zone 3a).

The input of those post-installation stresses require curve fitting, ensuring that equilibrium is fulfilled:

$$
\frac{\partial \sigma_{r}^{\prime}}{\partial r}+\frac{\sigma_{r}^{\prime}-\sigma^{\prime} \theta}{r}=0
$$

neglecting shear stresses to avoid unnecessary complexity.

For normal column spacings, the soil between the columns will be in Zone 3. Therefore, for the sake of simplicity, it is reasonable to assume the vertical and hoop stresses constant. For the radial stress, the following hyperbolic curve gives the best fit obeying Eq. (2):

$$
\frac{\sigma_{r}^{\prime}}{\sigma_{z 0}^{\prime}}=\frac{a}{r / r_{c}}+b
$$

where $a$ and $b$ are the fitting parameters. The value of those fitting parameters and the fitted curves are shown in Table 4 and Figure 7, respectively. 


\subsection{Void ratio and Overconsolidation}

Column installation not only alters the stress field but also the values for the state parameters of the soil, such as the void ratio (Figure 9). The void ratio decreases just near the column, less than 4.5-6 column radii (Zone 3). However, the densification is especially important in the area closer than 2 column radii (Zone 3a). Weber et al. [16] measured a similar value of 2.5 column radii for the densification area. They fitted the data points of porosity and density using a hyperbolic function; a similar function may be here proposed to fit the void ratio:

$$
e=e_{0}-\frac{a}{r / r_{c}-b}
$$

where $a$ and $b$ are the fitting parameters. The parameter $b$ must be lower than 1 because the void ratio cannot be negative. The value of those fitting parameters and the fitted curves are shown in Table 4 and Figure 9.

The results for MCC and S-CLAY1 are quite similar, but soil destructuration due to column installation causes a greater densification of the soil. The value of the void ratio is directly related to the changes in the mean effective stresses and the mobilized soil stiffness. The mean effective stresses, $p^{\prime}$, and the size of the yield surface, given by $p_{m}^{\prime}$, are plotted in Figure 10. The different zones previously distinguished are also visible here: (1) far from the column, the mean effective stresses does not change, (2) the mean effective stress increases but without expanding the yield surface because the overconsolidation ratio is $O C R=1.5$, (3) the current stress point is on the yield surface and (3a) the yield surface is notably expanded through strain hardening, $p_{m}^{\prime}$ increases (Figure 8). Note that the extension of these zones is slightly different depending on the soil model. The current mean effective stress, $p^{\prime}$, does not necessarily coincide with $p^{\prime}{ }_{m}$ when the point is on the yield surface (Figure 10) because $p_{m}^{\prime}$ is the mean effective 
stress at the apex of the yield surface (Figure 2) [23]. The relative expansion of the yield surface is similar for MCC and S-CLAY1, which explains the similar results for the void ratio. For S-CLAY1S, the intrinsic yield surface, $p^{\prime}{ }_{m i}$, is significantly expanded in Zone 3a. The densification or the strain hardening is only important in Zone 3a, i.e. for closely spaced columns.

\subsection{Anisotropy}

The advanced soil models S-CLAY1 and S-CLAY1S are used to reproduce the changes in soil fabric due to column installation. The inclination of the yield surface changes, as shown in Figure 11, where the components of the fabric tensor, $\left\{\alpha_{i}\right\}$, are plotted. The two anisotropic models predict almost identical changes in anisotropy. To study the influence that those changes have on the settlement reduction, they are input as initial values after their fitting. By definition of the fabric tensor [23], the fitting of those components must fulfilled that

$$
\frac{1}{3}\left(\alpha_{r}+\alpha_{\theta}+\alpha_{z}\right)=1
$$

For the sake of simplicity, it seems sensible to keep $\alpha_{\theta}$ constant and decrease $\alpha_{z}$ the same amount that $\alpha_{r}$ increases. For common column spacings, a straight line gives the best fit, $\alpha_{i}=a\left(r / r_{c}\right)+b$. The value of the fitting parameters $a$ and $b$ and the fitted straight lines are shown in Table 4 and Figure 11, respectively.

\subsection{Destructuration}

S-CLAY1S model reproduces the destructuration caused by column installation (Figure 12). The changes in the bonding parameter, $\chi$, which controls the size of the intrinsic yield surface (Figure 10), $p^{\prime}{ }_{m}=p^{\prime}{ }_{m i}(1+\chi)$, are fitted using the following hyperbolic curve 


$$
\chi / \chi_{0}=a\left(1-\frac{1}{r / r_{c}}\right)
$$

The fitting curve accounts for full remoulding in the soil-column contact and should not be used for high column spacings to avoid values of the bonding parameter higher than the initial one.

\section{Soil improvement with installation effects}

After the evaluation of the changes in the stresses and the state parameters due to column installation and applying curve fitting, the soil improvement caused by the columns is analysed using the unit cell model (Figure 1). The fitting curves are used to input the initial values of the surrounding soil that account for the effects of installation. For the column, $\gamma$ and $K_{0}$ are adjusted to give the same vertical and radial stresses as those of the soil at their interface to ensure equilibrium. After that initialization of the stresses and state variables, a so-called "nil-step", i.e. a calculation step without any changes, is simulated to verify equilibrium and the correctness of the initial values. Then, the embankment is introduced in only one calculation phase, as its construction is simulated in drained conditions. The analysis of the results focuses on the settlement reduction factor, $\beta$, and the influence of the soil model (Figure 13).

To help to evaluate the influence of the changes in the state of soil due to column installation, a new parameter is introduced, $\beta^{*}$, which is the ratio between the settlement considering those changes and the settlement without them (Figure 14).

Interestingly, if the changes in the soil state due to column installation are considered, the settlement is not always reduced. A positive effect $\left(\beta^{*<1)}\right.$ is achieved for closely 
spaced columns and high embankment loads. Although no interaction effects were considered by the installation of several columns, the stress increment and other effects of installation are more evident near the columns (Zone 3a). The increment of radial stresses leads to a better lateral confinement of the columns and the increment of the preconsolidation pressure $\left(p_{m}^{\prime}\right)$ causes a strain hardening of the soil. Therefore, the settlement is reduced for closely spaced columns as expected. The effect of the embankment load was not so clearly foreseen, yet Schweiger [22] already found numerically that, if the effects of column installation are considered, the settlement was reduced only for high load levels. For low embankment loads, the soil is overconsolidated; the remoulding effect of the column installation erases the soil overconsolidation and, consequently, has a negative effect on the settlement reduction. There may be even no improvement $(\beta>1)$ for low loads. The soil considered in this analysis (Bothkennar clay) is only slightly overconsolidated $(O C R=1.5)$. In highly overconsolidated stiffer soils $(O C R>2)$, this remoulding effect may have a more negative influence on the settlement reduction. That has already been detected in the field; for example, Serridge and Sarsby [27] alert on the negative effect of column installation in the upper crust, which is clearly overconsolidated.

The S-CLAY1 model predicts a more positive effect of the column installation in the settlement reduction than MCC because it accounts for the soil anisotropy (Figure 14). On one hand, the radial stresses after column installation and consolidation are predicted to be higher for S-CLAY1 than MCC (Figure 7) and on the other hand, the changes in the soil anisotropy during installation (Figure 15) have a positive effect in reducing the settlement because energy is dissipated in the evolution of anisotropy. To help to visualize the changes in the soil fabric, Figure 16 shows the $\left(\alpha_{z}-\alpha_{\theta}, \alpha_{r}-\alpha_{\theta}\right)$ vector 
in arbitrary points. This vector changes from horizontal direction for an initial vertical cross anisotropy towards a nearly vertical one for radial cross anisotropy after column installation and consolidation. Fellenius and Samson [34] already measured in the field this type of soil fabric rotation caused by pile driving. Hansbo [35] proposed based on field experience that in the "smear zone" around a vertical drain, the horizontal permeability is proportional to the vertical one in the intact soil, which may be justified by the soil fabric rotation. The one dimensional compression caused by the embankment load rotates again the fabric vector towards the horizontal direction. Its length is equal to $\alpha_{0}=0.539$ for the initial situation, and this changes only slightly.

When the soil sensitivity is included (S-CLAY1S), the changes in the soil state due to column installation are less positive than for the S-CLAY1 model (Figure 14). The destructuration of the soil during column installation, considered as the decrease of $\chi$ (the amount of bonding), is on its own positive because the soil sensitivity prior to the embankment load is lower and therefore, the destructuration during the loading process is less important. However, the soil destructuration during column installation causes also a decrease of the preconsolidation pressure, $p_{m}^{\prime}$, and reduces the increase of the radial stresses (Figure 7c and Figure 10). Therefore, the overall effect of soil destructuration is negative.

Figure 14 demonstrates that including the changes in the soil state due to column installation is not always positive, it depends on each case and is difficult to quantify, as it is a function of column spacing, OCR and soil sensitivity. 


\section{Conclusions}

Numerical simulations using advanced soil models were performed to study the influence of stone column installation in reducing the settlement of a natural soft clay. For low loads and large column spacings, special care should be paid to column installation because it has a negative effect on the settlement reduction, especially in overconsolidated soils, which are clearly damaged by column installation.

Soil fabric plays a crucial role on the influence of the installation effects on the soil improvement. Soil anisotropy has a positive effect because of the rotation of the soil fabric and the increase of the radial stresses.

As a summary, the following changes in the state of the soil due to column installation have a positive influence on the settlement reduction:

a) increase of the radial stresses, which laterally confined the column;

b) strain hardening of the soil, i.e. increase of the preconsolidation pressure, which increases the soil stiffness, related to this effect is the reduction of the void ratio;

c) change of the soil anisotropy, from cross (horizontal) anisotropy to vertical and again to horizontal after embankment loading;

and the following have a negative influence:

d) decrease of the $O C R$, which increases the soil plastic strains;

e) soil destructuration, which leads to lower stress increments, specially radial ones, and diminishes the improvement, and 
f) excess pore pressures, which have been assumed as fully dissipated in this paper but, if still present when the embankment is going to be elevated, cause some soil consolidation and reduce the effective stresses.

\section{Acknowledgements}

The research was carried out as part of a Marie Curie Industry-Academia Partnerships and Pathways project on "Modelling Installation Effects in Geotechnical Engineering (GEO-INSTALL)” (PIAP-GA-2009-230638). 


\section{References}

[1] Barksdale RT, Bachus RC. Design and construction of stone columns. Report FHWA/RD-83/026. Springfield: Nat Tech Information Service; 1983.

[2] Balaam NP, Booker JR. Effect of stone column yield on settlement of rigid foundations in stabilized clay. Int J Num Anal Meth Geomech 1985; 9(4): 331351.

[3] Castro J, Sagaseta C. Consolidation around stone columns. Influence of column deformation. Int J Numer Anal Meth Geomech 2009; 33(7): 851-877.

[4] Priebe HJ. Design of vibro replacement. Ground Eng 1995; 28(10): 31-37.

[5] Egan D, Scott W, McCabe B. Installation effects of vibro replacement stone columns in soft clay. Geotechnics of Soft Soils - Focus on Ground Improvement, Glasgow, 3-5 September 2008. Taylor and Francis, London, pp. 23-29.

[6] Slocombe BC, Bell AL, Baez JI. The densification of granular soil using Vibro methods. Géotechnique 2000; 50(6): 715-726.

[7] Massarsch KR, Fellenius BH. Vibratory compaction of coarse-grained soils. Can Geotech J 2002; 39(3): 695-709.

[8] Arnold M, Herle I. 2009. Comparison of vibrocompaction methods by numerical simulations. Int J Numer Anal Meth Geomech 2009; 33(16): 1823-1838.

[9] Farias MM, Nakai T, Shahin HM, Pedroso DM, Passos PGO, Hinokio M. 2005. Ground densification due to sand compaction piles. Soils Foundations 2005; 45(2): 167-180. 
[10] Watts KS, Johnson D, Wood LA, Saadi A. 2000. An instrumented trial of vibro ground treatment supporting strip foundations in a variable fill. Géotechnique 2000; 50(6): 699-708.

[11] Watts KS, Chown RC, Serridge CJ. Vibro stone columns in soft clay: A trial to study the influence of column installation on foundation performance. Proc $15^{\text {th }}$ Int Conf Soil Mech Geotech Eng, Istanbul, 28-31 August 2001. Taylor and Francis, London, pp. 1867-1870.

[12] Kirsch F. Experimentelle und numerische Untersuchungen zum Tragverthalten von Rüttelstopfsäulengruppen. Dissertation, Technische Universität Braunschweig; 2004.

[13] Gäb M, Schweiger HF, Thurner R, Adam D. Field trial to investigate the performance of a floating stone column foundation. Proc $14^{\text {th }}$ European Conf Soil Mech Geotech Eng, Madrid, 24-27 September 2007. Millpress, Amsterdam, pp. 1311-1316.

[14] Castro J, Sagaseta C. Pore pressure during stone column installation. Proc ICE Ground improvement 2012; 165(2): 97-109.

[15] Lee FH, Juneja A, Tan TS. Stress and pore pressure changes due to sand compaction pile installation in soft clay. Géotechnique 2004; 54(1): 1-16.

[16] Weber TM, Plötze M, Laue J, Peschke G, Springman SM. Smear zone identification and soil properties around stone columns constructed in-flight in centrifuge model tests. Géotechnique 2010; 60(3): 197-206.

[17] Carter JP, Randolph MF, Wroth CP. Stress and pore pressure changes in clay during and after the expansion of a cylindrical cavity. Int J Num Anal Meth Geomech 1979; 3(4): 305-322. 
[18] Yu HS. Cavity expansion methods in geomechanics. Kluwer Academic, London; 2000

[19] Kirsch F. Vibro stone column installation and its effect on ground improvement. Proc Num Modelling Construction Processes Geotech Eng Urban Environment, Bochum, Germany, 23-24 March 2006. Taylor and Francis, London, pp. 115-124.

[20] Guetif Z, Bouassida M, Debats JM. Improved soft clay characteristics due to stone column installation. Computers Geotech 2007; 34(2): 104-111.

[21] Castro J, Karstunen M. Numerical simulations of stone column installation. Can Geotech J 2010; 47(10): 1127-1138.

[22] Schweiger HF. Finite element analysis of stone column reinforced foundations. PhD Thesis, University of Wales, Swansea; 1989.

[23] Wheeler SJ, Naatanen A, Karstunen K, Lojander M. An anisotropic elastoplastic model for soft clays. Can Geotech J 2003; 40(2): 403-418.

[24] Karstunen M, Krenn H, Wheeler SJ, Koskinen M, Zentar R. Effect of anisotropy and destructuration on the behavior of Murro test embankment. ASCE Int $\mathbf{J}$ Geomech 2005; 5(2): 87-97.

[25] Roscoe KH, Schofield AN, Wroth CP. On the yielding of soils. Géotechnique 1958; 8(1): 22-53.

[26] Brinkgreve RBJ. Plaxis finite element code for soil and rock analysis, 2D, version 9. Balkema, Rotterdam; 2008.

[27] Serridge CJ, Sarsby RW. A review of field trials investigating the performance of partial depth vibro stone columns in a deep soft clay deposit. Geotechnics of Soft 
Soils - Focus on Ground Improvement, Glasgow, 3-5 September 2008. Taylor and Francis, London, pp. 293-298.

[28] Géotechnique Symposium in print. Bothkennar soft clay test site: characterisation and lessons learned. Géotechnique 1992; 42(2).

[29] Sivasithamparam, N. Development and implementation of advanced soft soil models in finite elements. PhD thesis, University of Strathlcyde, Glasgow; 2012.

[30] Biot, M.A. General solutions of the equations of elasticity and consolidation for a porous material. J Applied Mech 1956; 23 (2): 91-96.

[31] Elshazly HA, Hafez D, Mosaad M. Back calculating vibro-installation stresses in stone columns reinforced grounds. Proc ICE - Ground improvement 2006; 10(2): $47-53$.

[32] Elshazly HA, Elkasabgy M, Elleboudy A. Effect of inter-column spacing on soil stresses due to vibro-installed stone columns: interesting findings. J Geotech Geological Eng 2008; 26: 225-236.

[33] Potts DM, Zdravkovic L. Finite element analysis in geotechnical engineering: theory. Thomas Telford, London; 1999.

[34] Fellenius BH, Samson L. Testing of drivability of concrete piles and disturbance to sensitive clay. Can Geotech J 1976, 13(1): 139-160.

[35] Hansbo S. Aspects of vertical drain design: Darcian or non-Darcian flow. Géotechnique 1997; 47(5): 983-992. 


\section{List of symbols}

A Area

$a_{r} \quad$ Area replacement ratio: $a_{r}=A_{c} / A_{l}$

$a, b \quad$ Constants of the hyperbolic fits for the installation effects / Absolute and relative effectiveness of destructuration in S-CLAY1S

c Cohesion

$c_{u} \quad$ Undrained shear strength

E Young's modulus

$E_{m} \quad$ Oedometric (constrained) modulus: $E_{m}=[E(1-v)][(1+v)(1-2 v)]$

e Void ratio (state parameter)

H Embankment height

$K_{0, N C}$ Coefficient of lateral earth pressure at rest in normally consolidated conditions

$K_{0} \quad$ Coefficient of lateral earth pressure at rest

$K_{i} \quad$ Coefficient of lateral earth pressure after column installation

$L \quad$ Column length and thickness of the soft soil layer

M Slope of the critical state line

$N \quad$ Column spacing ratio: $N=r_{l} / r_{c}$

$n \quad$ Improvement factor

$p_{a} \quad$ Applied vertical pressure

$p^{\prime} \quad$ Effective mean stress

$p_{m}^{\prime} \quad$ Preconsolidation pressure (state parameter)

$p_{m i}^{\prime} \quad$ Intrinsic preconsolidation pressure (state parameter): $p_{m i}^{\prime}=p_{m}^{\prime}(1+\chi)$

$q \quad$ Deviatoric stress

$r \quad$ Distance from column axis 
$r l, r_{c} \quad$ Radius of the unit cell, of the column

$S z \quad$ Settlement

$S z 0 \quad$ Settlement without columns

$\alpha \quad$ Inclination of the yield surface (state parameter)

$\beta \quad$ Settlement reduction factor / Relative effectiveness of rotational hardening in SCLAY1

$\beta^{*} \quad$ Ratio of the settlement with and without installation effects

$\chi \quad$ Amount of bonding in S-CLAY1S (state parameter)

$\gamma \quad$ Unit weight

$\varepsilon \quad$ Strain

$\eta \quad$ Stress ratio: $\eta=q / p^{\prime}$

$\theta \quad$ Lode's angle

$\kappa \quad$ Slope of swelling line from $e-\ln p^{\prime}$ diagram

$\lambda \quad$ Slope of post yield compression line from $e-\ln p^{\prime}$ diagram

$\lambda_{i} \quad$ Slope of intrinsic post yield compression line from $e-\ln p^{\prime}$ diagram

$\mu \quad$ Absolute effectiveness of rotational hardening in S-CLAY1

$v \quad$ Poisson's ratio

$\sigma^{\prime} \quad$ Effective stress

$\phi \quad$ Friction angle

$\psi \quad$ Dilatancy angle

OCR Overconsolidation ratio

$P O P$ Pre-overburden pressure 


\section{Subscripts/superscripts:}

$\begin{array}{ll}0 & \text { initial } \\ C S & \text { at critical state } \\ d, v & \text { deviatoric, volumetric } \\ e, c, s, l & \text { embankment, column, soil, elementary cell } \\ p & \text { plastic } \\ r, z, \theta & \text { cylindrical coordinates } \\ \text { unsat, sat } & \text { unsaturated, saturated }\end{array}$




\section{Table captions}

Table 1. S-CLAY1S parameters for Bothkennar clay.

Table 2. Embankment and stone column parameters.

Table 3. Comparison between drained (D) and consolidation (C) loading. Reference case without installation effects $(H=5 \mathrm{~m})$.

Table 4. Curve fitting of initial stresses and state parameters. 
Table 1. S-CLAY1S parameters for Bothkennar clay.

\begin{tabular}{|c|c|c|c|c|c|c|c|c|c|c|c|c|c|c|c|c|}
\hline \multirow[b]{2}{*}{$\begin{array}{l}\text { Depth } \\
\text { (m) }\end{array}$} & \multicolumn{9}{|c|}{ Basic parameters } & \multicolumn{3}{|c|}{ Anisotropy } & \multicolumn{4}{|c|}{ Bonding } \\
\hline & $\begin{array}{l}\gamma \\
\left(\mathrm{kN} / \mathrm{m}^{3}\right)\end{array}$ & $e_{0}$ & $O C R$ & $\begin{array}{l}P O P \\
(\mathrm{kPa})\end{array}$ & $K_{0}$ & $\kappa$ & $v^{\prime}$ & $\lambda$ & $M$ & $\alpha_{0}$ & $\mu$ & $\beta$ & $\chi_{0}$ & $\lambda_{i}$ & $a$ & $b$ \\
\hline $0-1$ & 18.0 & 1.1 & - & 30 & 1.35 & 0.02 & 0.2 & 0.48 & 1.4 & 0.539 & 30 & 0.94 & 5 & 0.18 & 11 & 0.2 \\
\hline $1-10$ & 16.5 & 2 & 1.5 & - & 0.544 & 0.02 & 0.2 & 0.48 & 1.4 & 0.539 & 30 & 0.94 & 5 & 0.18 & 11 & 0.2 \\
\hline
\end{tabular}


Table 2. Embankment and stone column parameters.

\begin{tabular}{lccccccc}
\hline & $\begin{array}{c}\gamma_{\text {unsat }} \\
\left(\mathrm{kN} / \mathrm{m}^{3}\right)\end{array}$ & $\begin{array}{c}\gamma_{\text {sat }} \\
\left.\mathrm{kN} / \mathrm{m}^{3}\right)\end{array}$ & $\begin{array}{c}c \\
(\mathrm{kPa})\end{array}$ & $\begin{array}{c}\phi \\
\left({ }^{\circ}\right)\end{array}$ & $\begin{array}{c}\psi \\
\left({ }^{\circ}\right)\end{array}$ & $\begin{array}{c}v \\
(-)\end{array}$ & $\begin{array}{c}E \\
(\mathrm{MPa})\end{array}$ \\
\hline Embankment & 22 & 22 & 10 & 35 & 0 & 0.3 & 40 \\
Stone column & 16 & 19 & 0.1 & 42 & 12 & 0.2 & 35 \\
\hline
\end{tabular}


Table 3. Comparison between drained (D) and consolidation (C) loading. Reference case without installation effects $(H=5 \mathrm{~m})$.

\begin{tabular}{l|cc|rr|rc|}
\hline Settlement (cm) & \multicolumn{2}{|c|}{$N=2$} & \multicolumn{2}{c|}{$N=3$} & \multicolumn{2}{c|}{$N=5$} \\
& $\mathrm{C}$ & $\mathrm{D}$ & \multicolumn{1}{|c}{$\mathrm{C}$} & \multicolumn{1}{c|}{$\mathrm{D}$} & $\mathrm{C}$ & $\mathrm{D}$ \\
\hline MCC & 38.1 & 37.6 & 88.1 & 88.0 & 129.6 & 130.2 \\
S-CLAY1 & 50.1 & 50.3 & 101.5 & 101.2 & 137.4 & 140.6 \\
S-CLAY1S & 42.2 & 41.8 & 78.5 & 77.7 & 102.2 & 103.7 \\
\hline
\end{tabular}


Table 4. Curve fitting of initial stresses and state parameters.

(a) Void ratio: $e=2-\frac{a}{r / r_{c}-b}$

\begin{tabular}{lccc}
\hline & \multicolumn{3}{c}{ Fit } \\
& $\mathrm{a}$ & $\mathrm{b}$ & $\mathrm{r}^{2}$ \\
\hline MCC & 0.0491 & 0.774 & 0.998 \\
S-CLAY1 & 0.0615 & 0.741 & 0.996 \\
S-CLAY1S & 0.0838 & 0.796 & 0.988 \\
\hline r. Pearson's correlation
\end{tabular}

(b) Radial stress: $\frac{\sigma_{r}^{\prime}}{\sigma_{z 0}^{\prime}}=\frac{a}{r / r_{c}}+b$

\begin{tabular}{lccc}
\hline & \multicolumn{3}{c}{ Fit } \\
& $\mathrm{a}$ & $\mathrm{b}$ & $\mathrm{r}^{2}$ \\
\hline MCC & 0.595 & 1.270 & 0.996 \\
S-CLAY1 & 1.210 & 0.828 & 1.000 \\
S-CLAY1S & 0.597 & 0.784 & 0.965 \\
\hline
\end{tabular}

r: Pearson's correlation coefficient

(c) Vertical and hoop stresses: constant (average values)

\begin{tabular}{lcccc}
\hline & \multicolumn{3}{c}{$\sigma_{z}^{\prime} / \sigma_{z 0}^{\prime}$} & $\sigma_{\theta}^{\prime} / \sigma_{z 0}^{\prime}$ \\
& $N=2$ & $N=3$ & $N=5$ & \\
\hline MCC & 1.394 & 1.297 & 1.232 & 1.270 \\
S-CLAY1 & 1.086 & 1.062 & 1.100 & 0.828 \\
S-CLAY1S & 0.755 & 0.845 & 0.992 & 0.784 \\
\hline
\end{tabular}

(d) Anisotropy: $\alpha_{i}=a\left(r / r_{c}\right)+b$

\begin{tabular}{lll}
\hline \multicolumn{3}{c}{ Fit } \\
& $\mathrm{a}$ & $\mathrm{b}$ \\
\hline$\alpha_{r}$ & -0.095 & 1.46 \\
$\alpha_{\theta}$ & 0.000 & 0.77 \\
$\alpha_{z}$ & 0.095 & 0.77 \\
\hline
\end{tabular}

(e) Destructuration $\chi / \chi_{0}=a\left(1-\frac{1}{r / r_{c}}\right)$

\begin{tabular}{ccc}
\hline & \multicolumn{2}{c}{ Fit } \\
& $\mathrm{a}$ & $\mathrm{r}^{2}$ \\
\hline S-CLAY1S & 1.13 & 0.975 \\
\hline
\end{tabular}

r: Pearson's correlation coefficient 


\section{Figure captions}

Figure 1. Example of the numerical model and the finite element mesh $(N=5)$.

Figure 2. Yield surfaces of the S-CLAY1S model [24].

Figure 3. Reference settlement without columns.

Figure 4. One dimensional compression of the soil.

Figure 5. Settlement with columns without installation effects.

Figure 6. Settlement reduction without installation effects.

Figure 7. Effective stresses after column installation and consolidation: (a) MCC; (b) SCLAY1; (c) SCLAY1S.

Figure 8. Stress paths.

Figure 9. Hyperbolic fit of the void ratio after column installation and consolidation.

Figure 10. Size of the yield surface and effective mean stresses after column installation and consolidation.

Figure 11. Components of the fabric tensor after column installation and consolidation.

Figure 12. Bonding parameter after column installation and consolidation.

Figure 13. Settlement reduction with installation effects: (a) MCC; (b) SCLAY1; (c) SCLAY1S.

Figure 14. Ratio of the settlement with and without installation effects: (a) $N=2$; (b) $N=3$; (c) $N=5$.

Figure 15. Change in the components of the fabric tensor after embankment loading.

Figure 16. Visualization of the soil fabric: (a) before column installation; (b) after column installation and consolidation; (c) after embankment loading. 


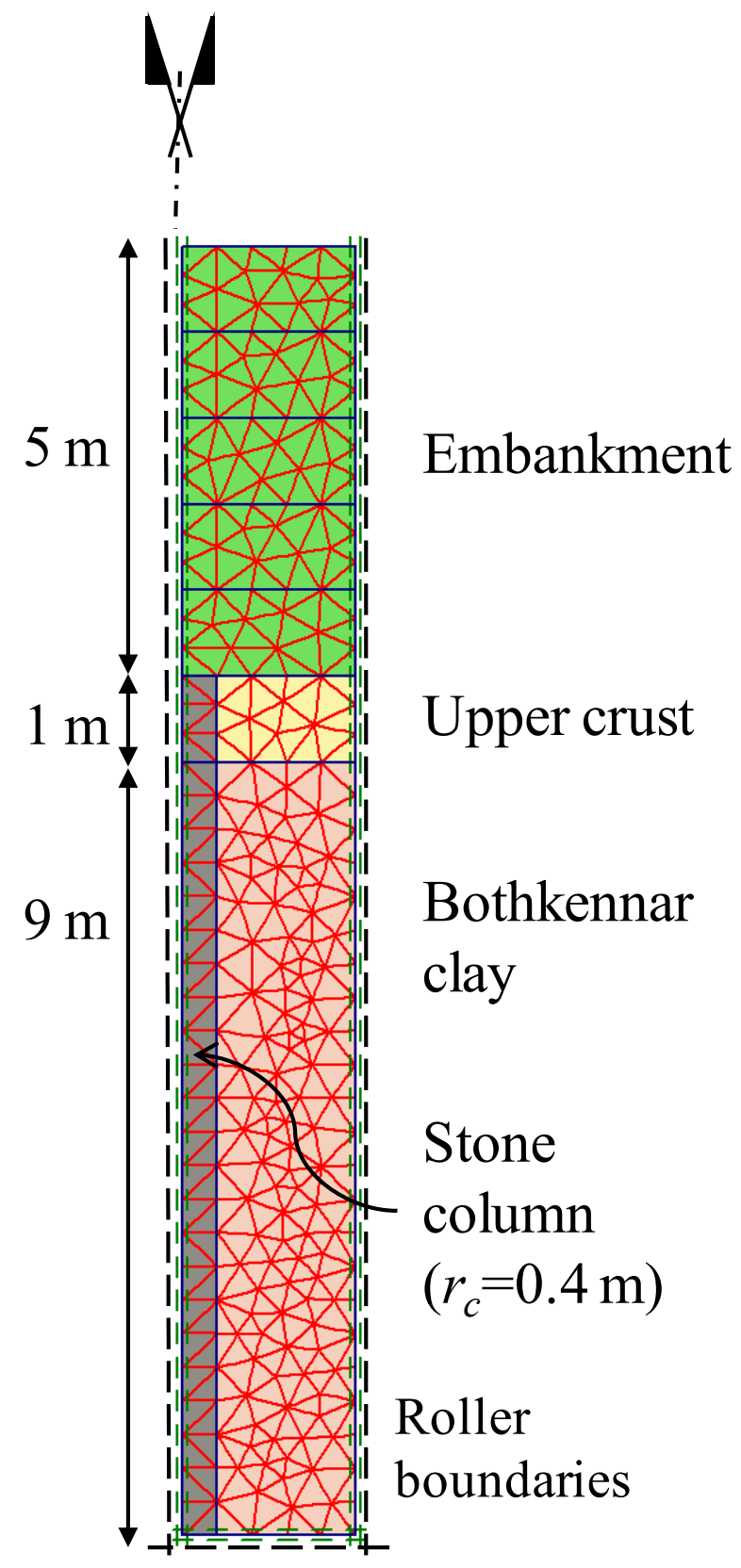

Figure 1. Example of the numerical model and the finite element mesh $(N=5)$. 


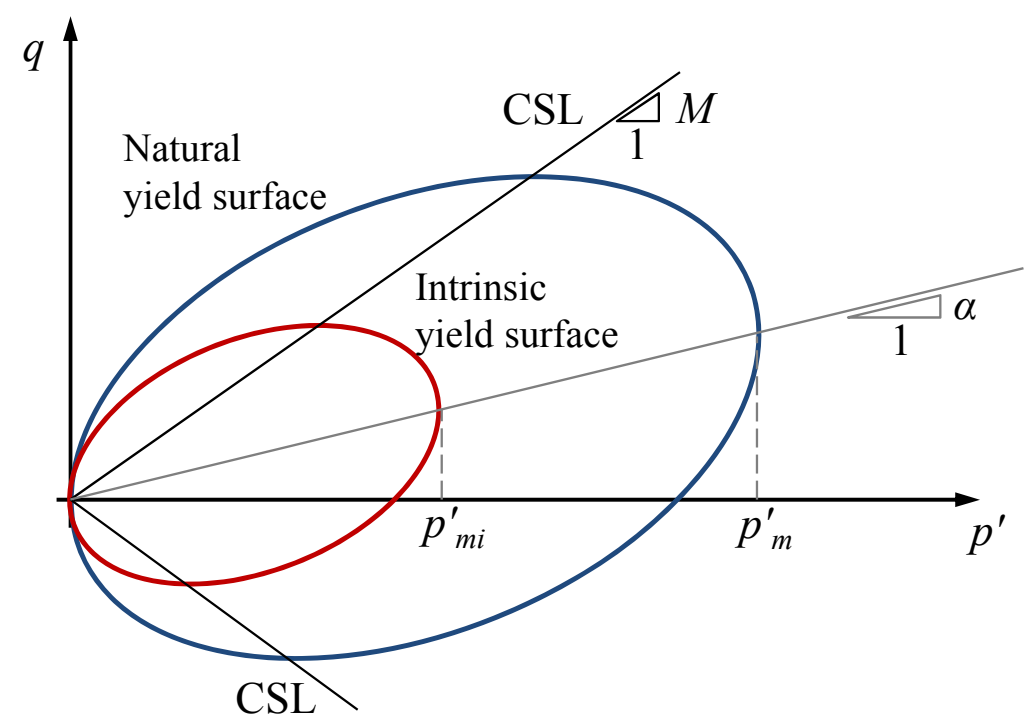

Figure 2. Yield surfaces of the S-CLAY1S model [24]. 


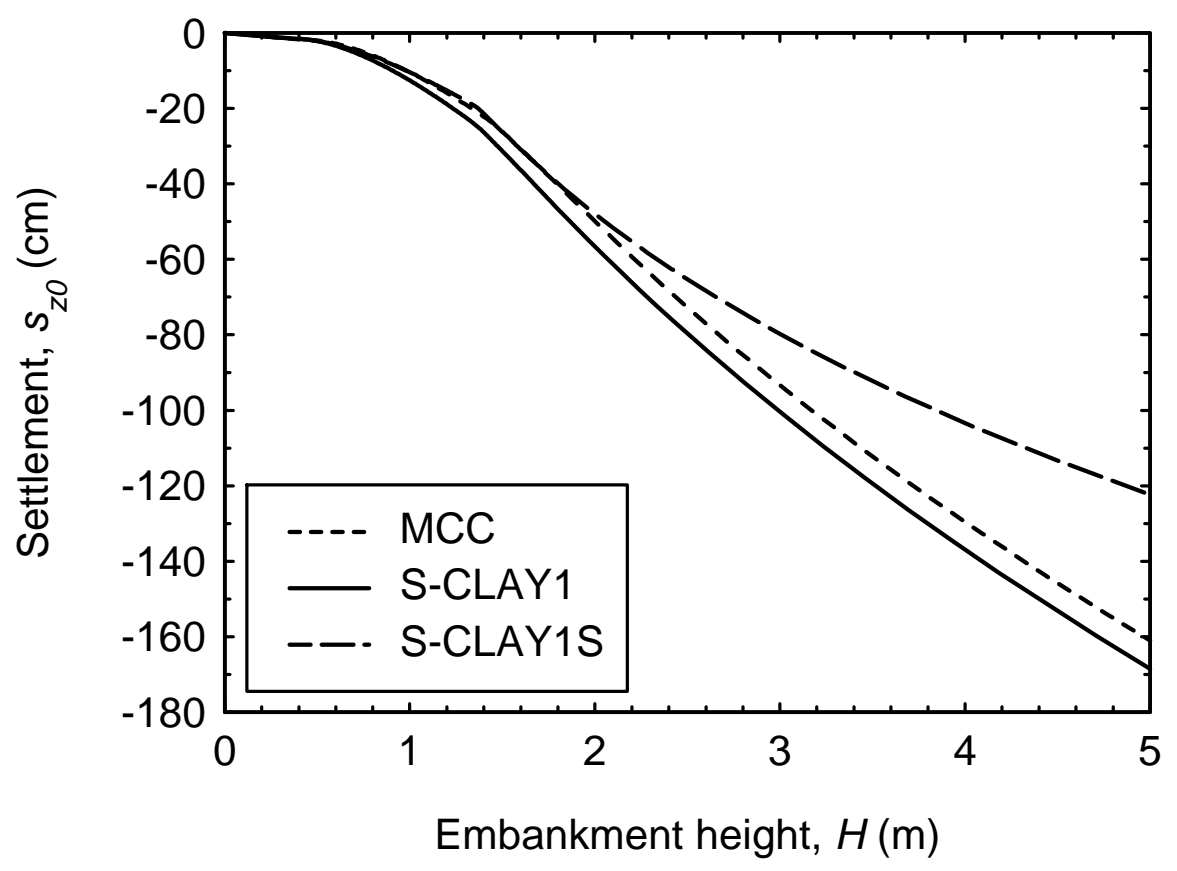

Figure 3. Reference settlement without columns. 


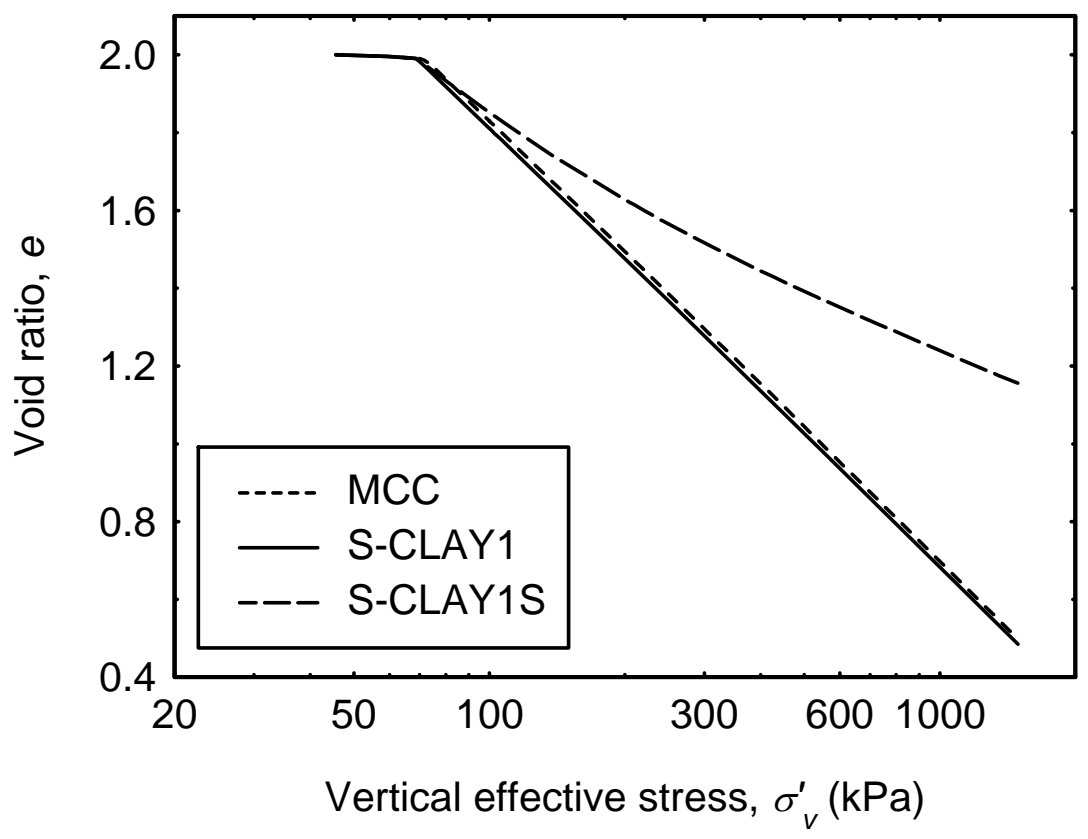

Figure 4. One dimensional compression of the soil. 


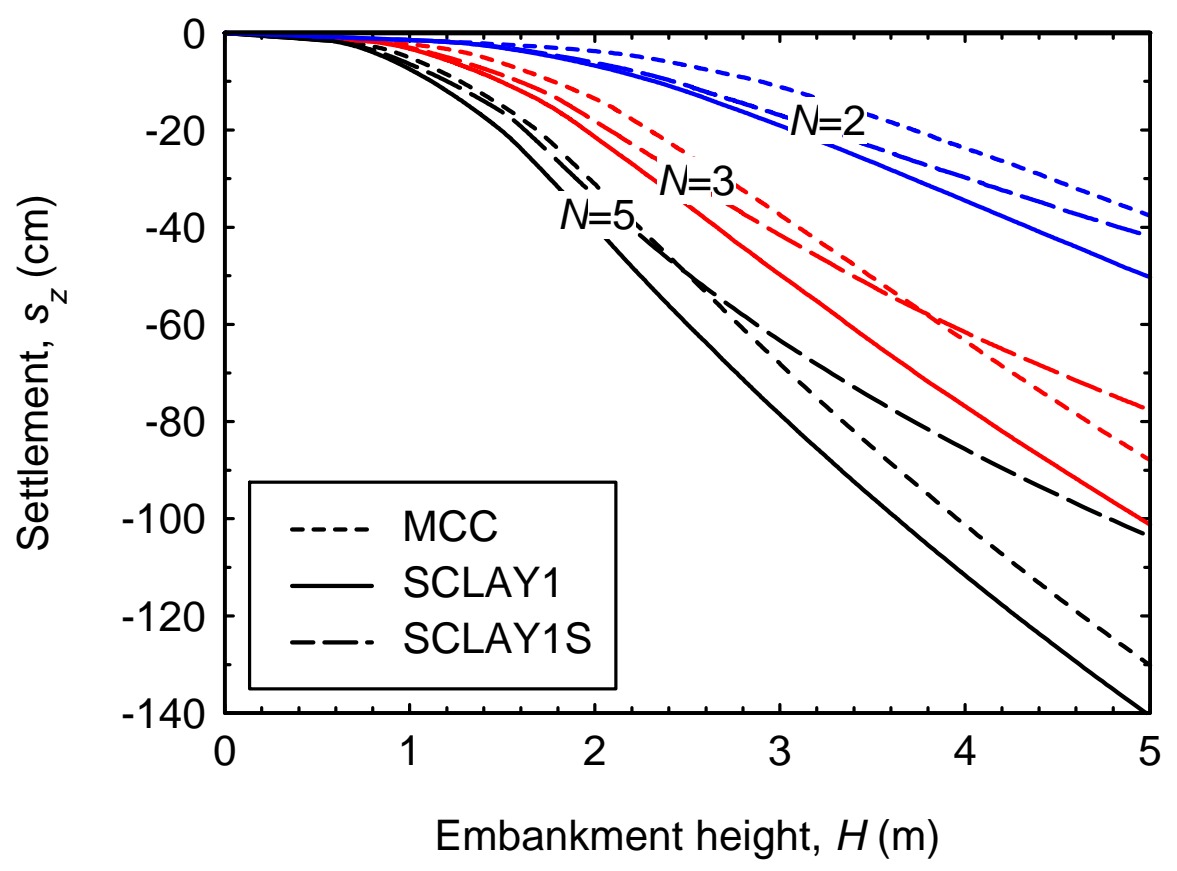

Figure 5. Settlement with columns without installation effects. 


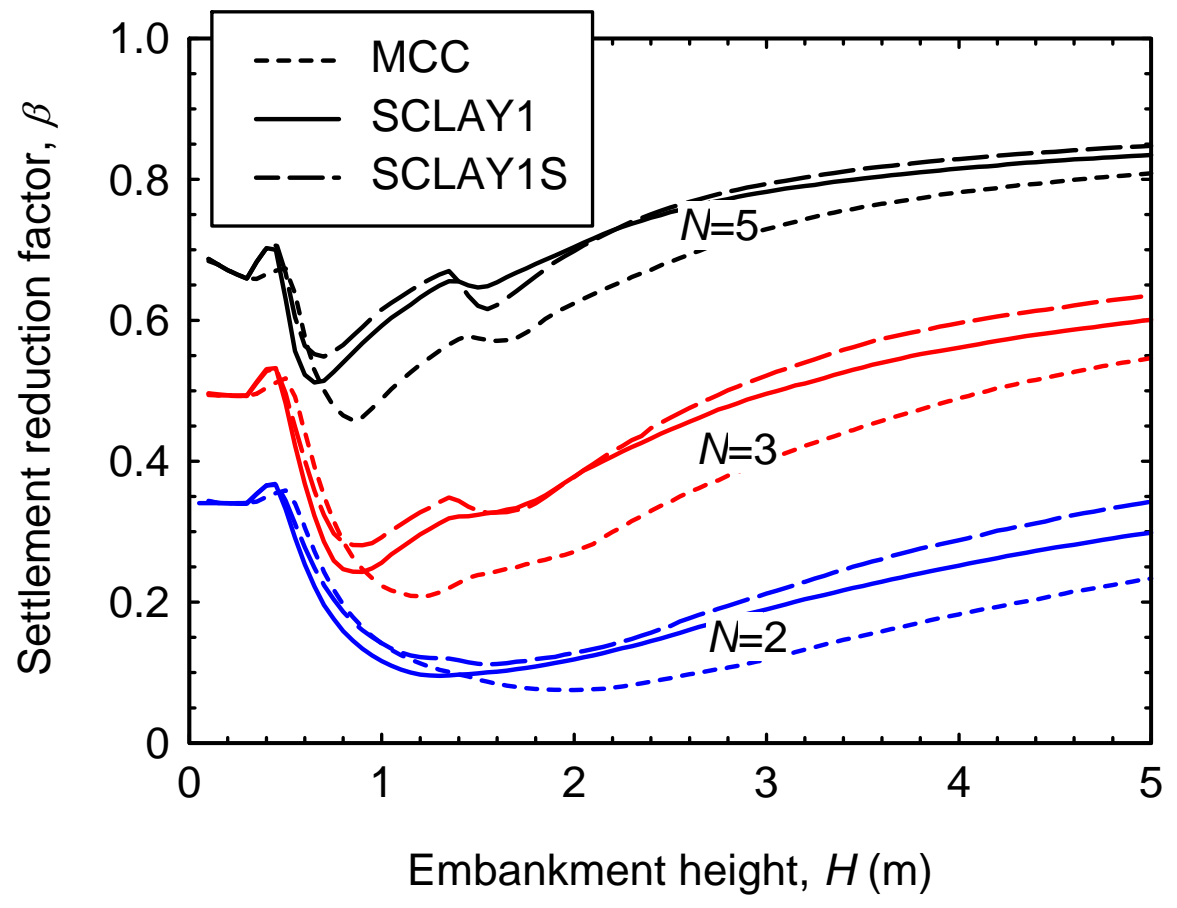

Figure 6. Settlement reduction without installation effects. 

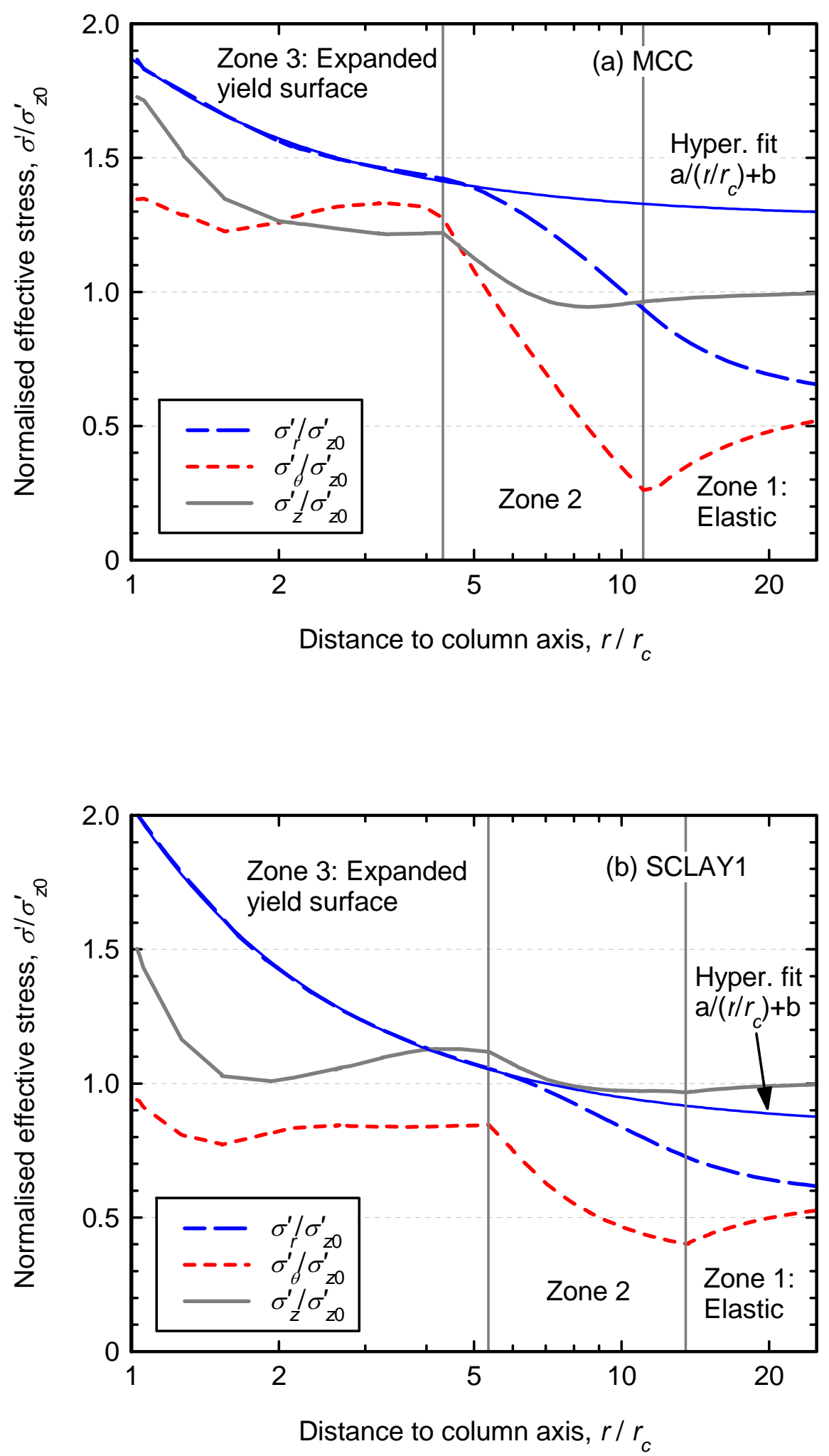


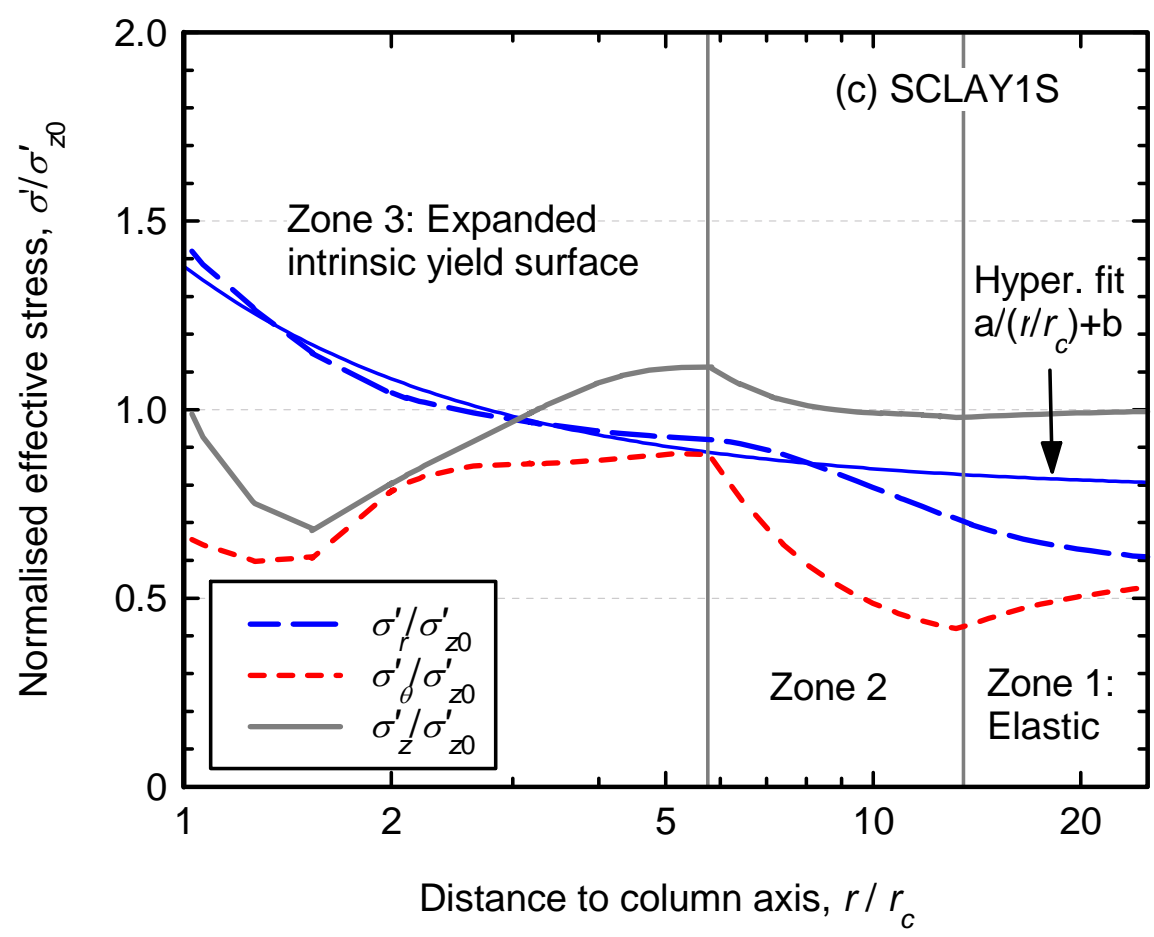

Figure 7. Effective stresses after column installation and full consolidation. 


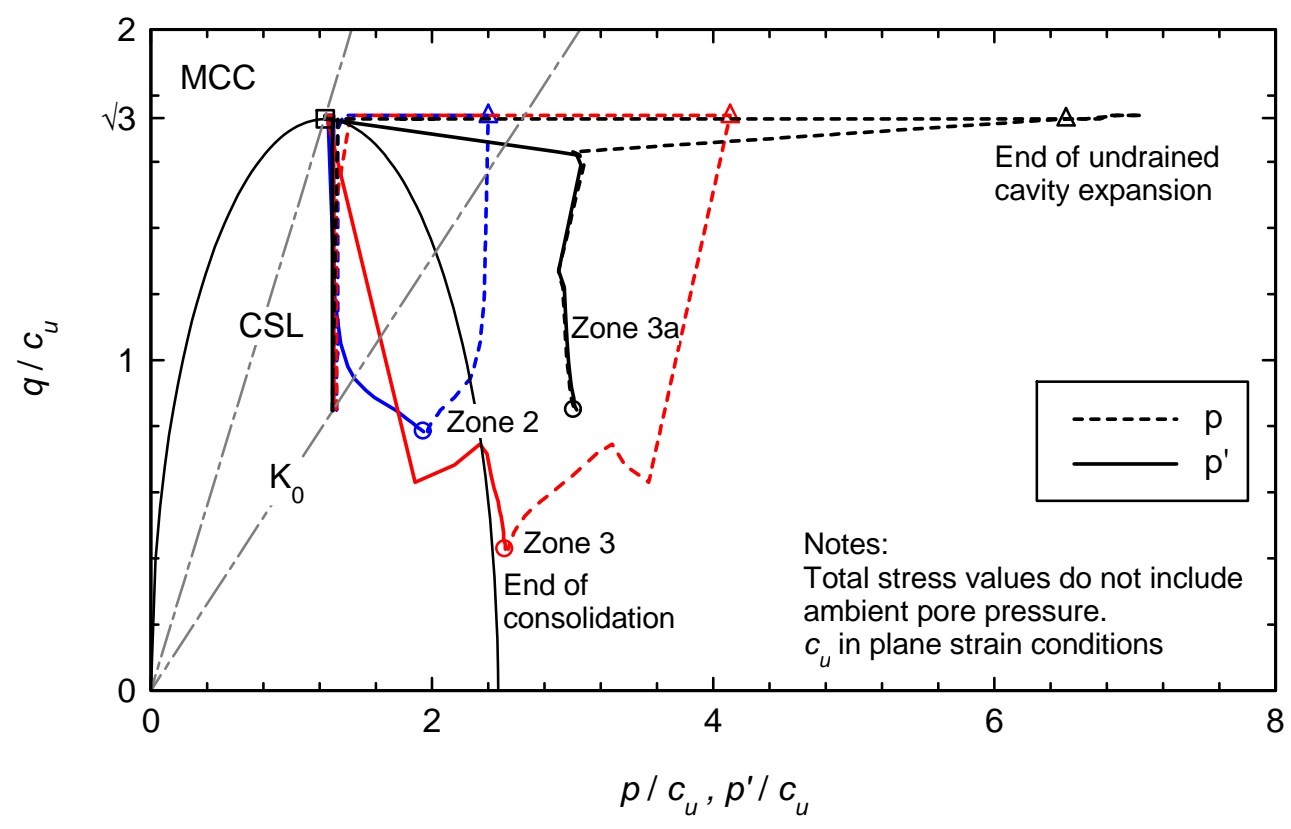

Figure 8. Stress paths. 


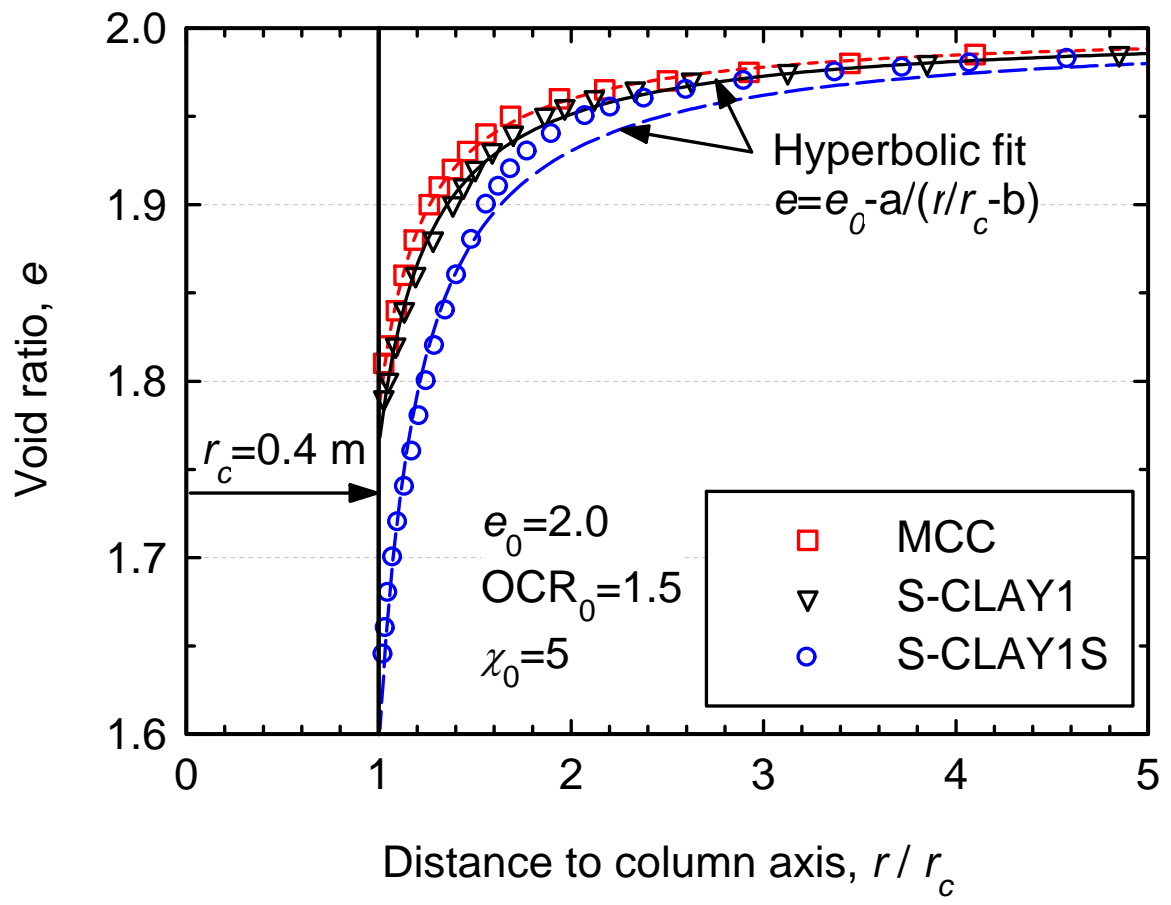

Figure 9. Hyperbolic fit of the void ratio after column installation and consolidation. 


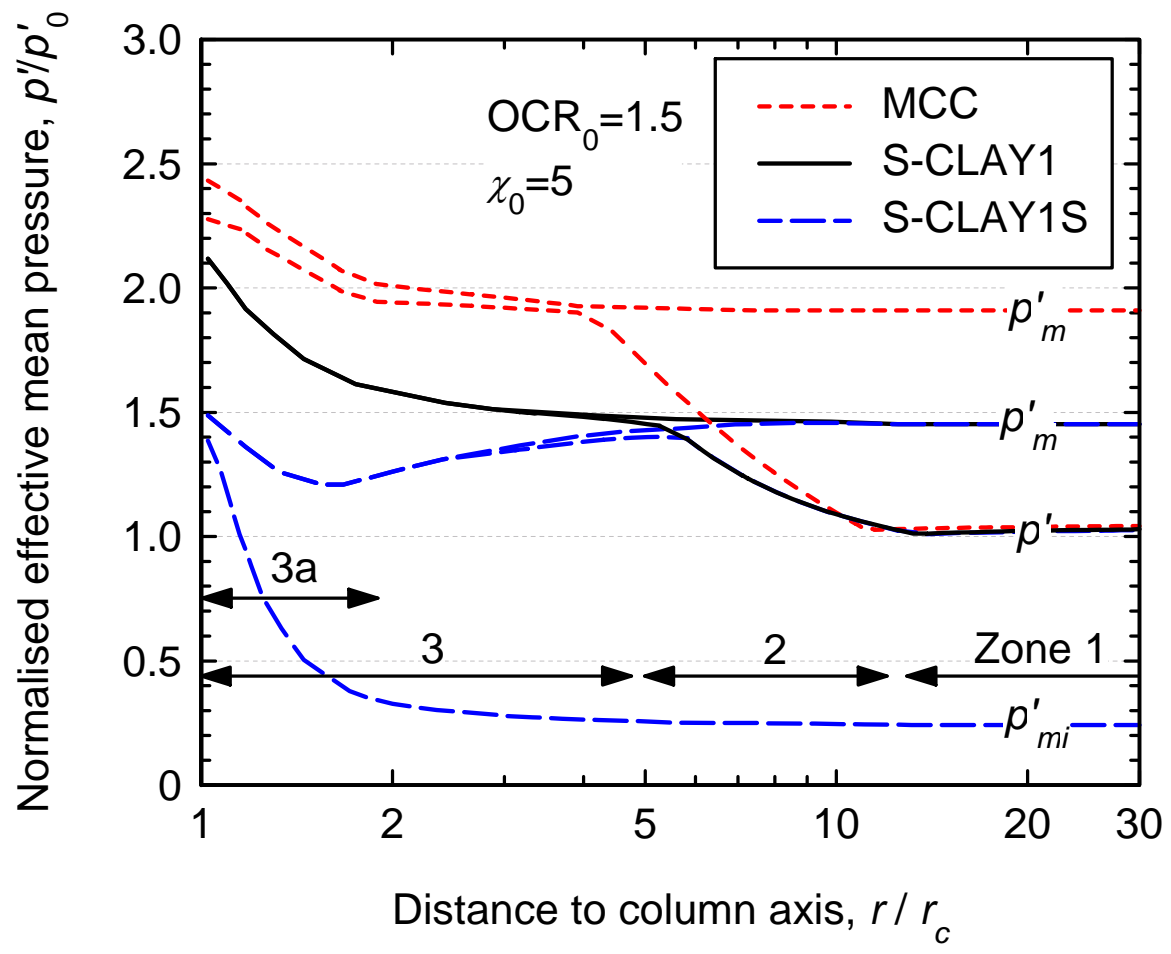

Figure 10. Size of the yield surface and effective mean stresses after column installation and consolidation. 


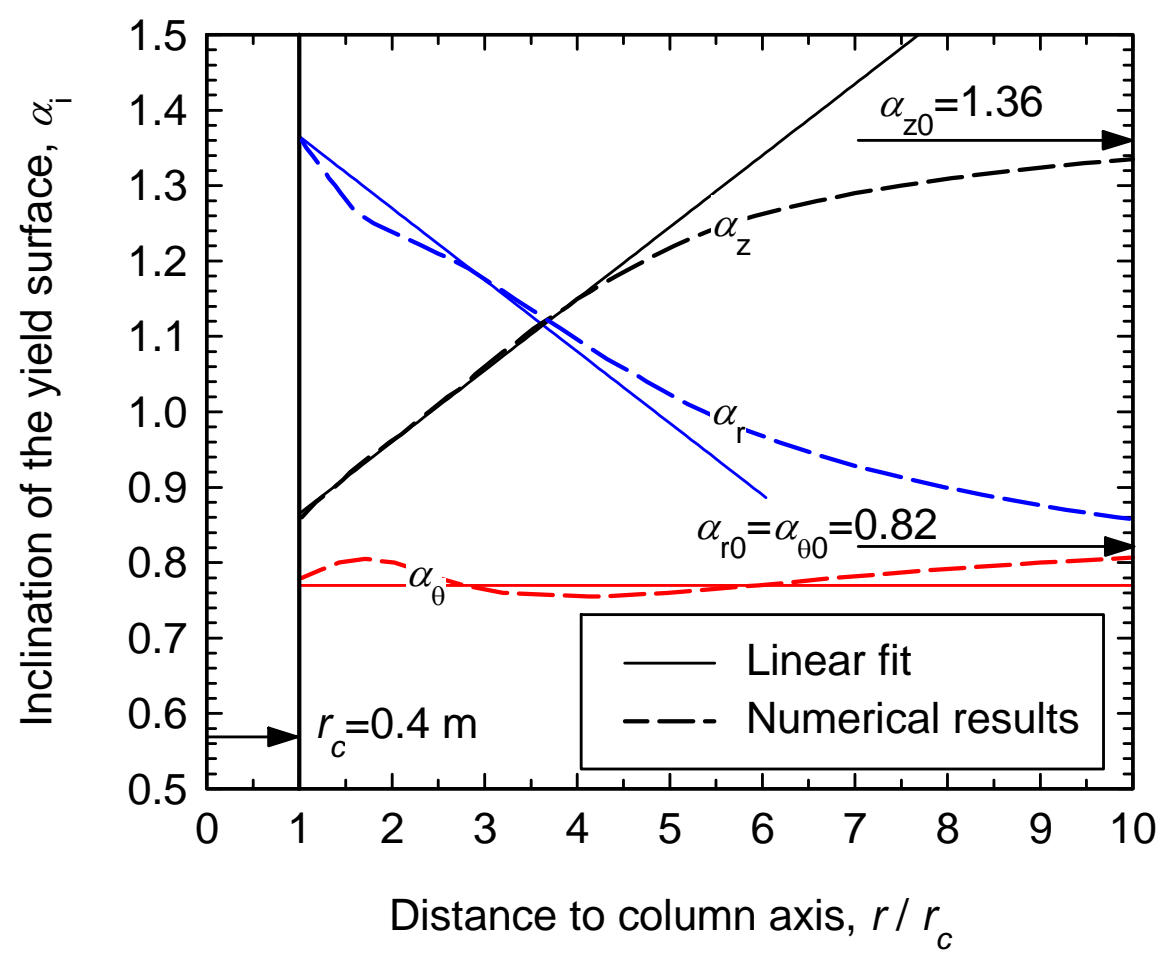

Figure 11. Components of the fabric tensor after column installation and consolidation. 


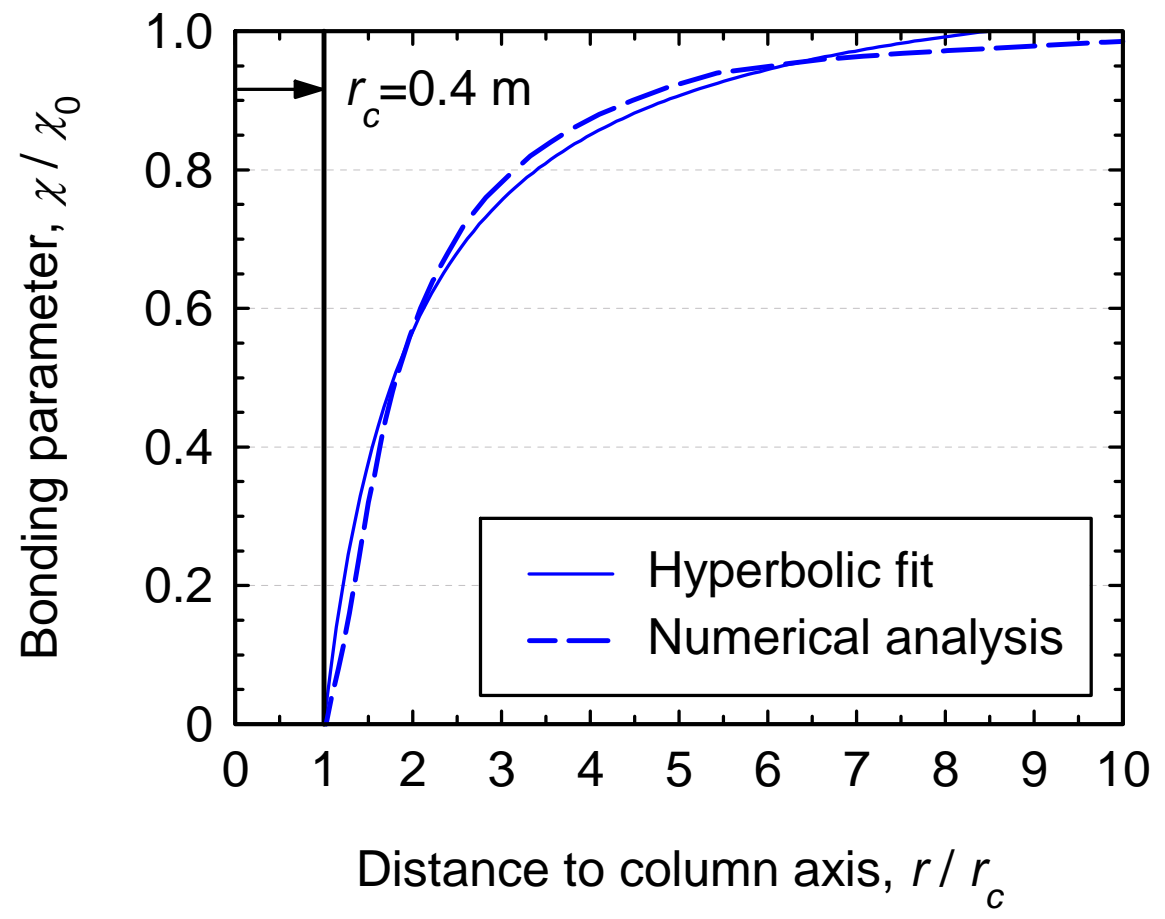

Figure 12. Bonding parameter after column installation and consolidation. 

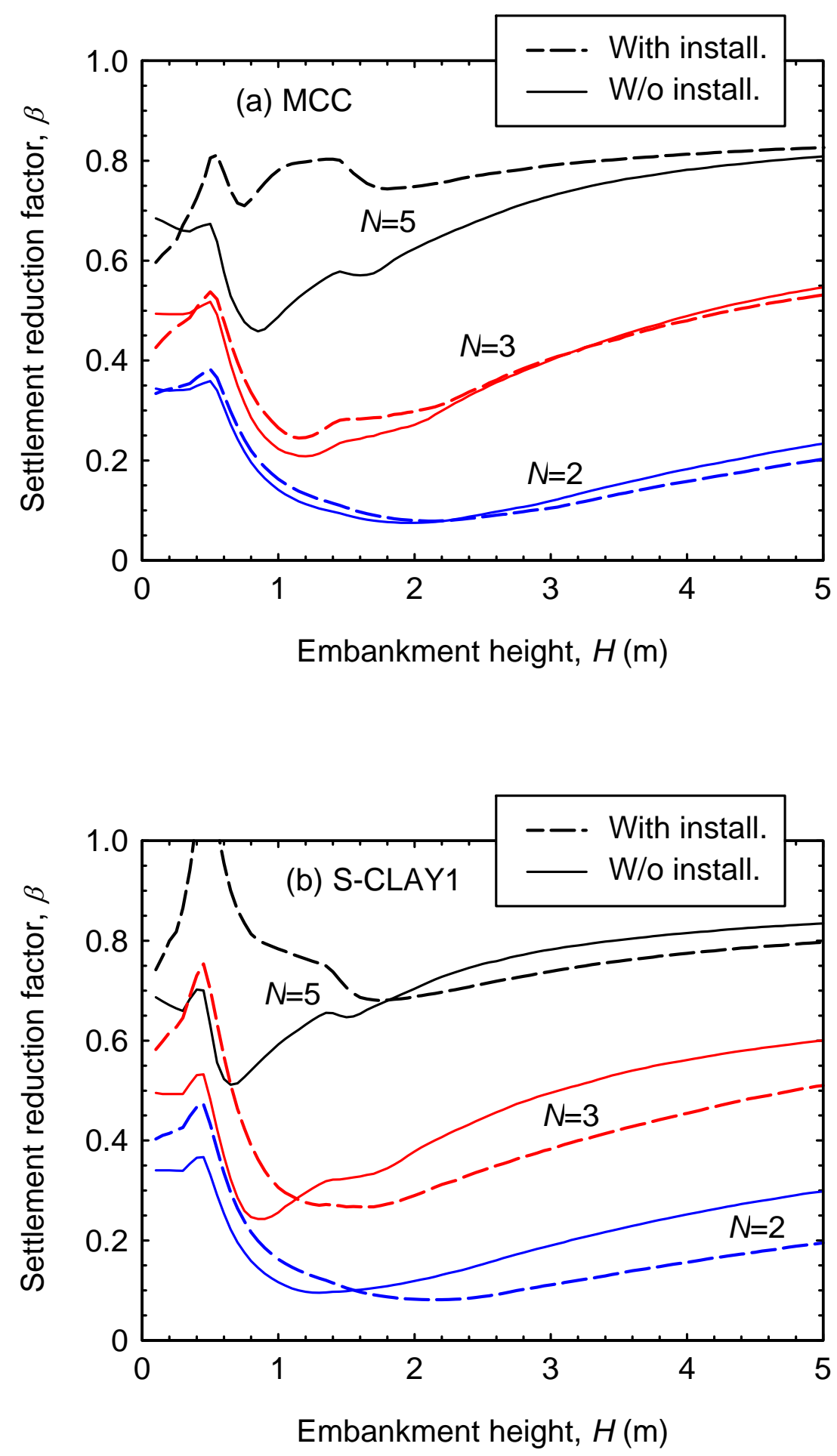


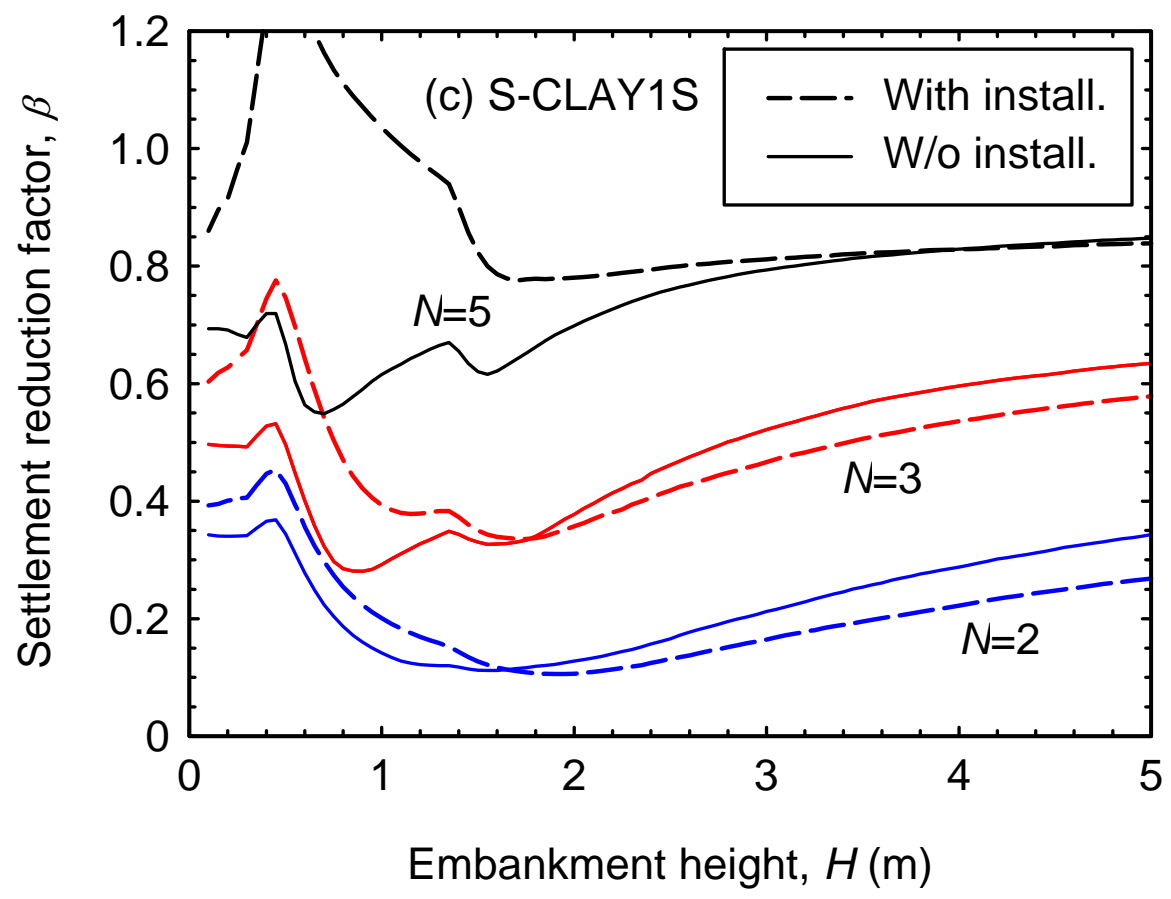

Figure 13. Settlement reduction with installation effects. 

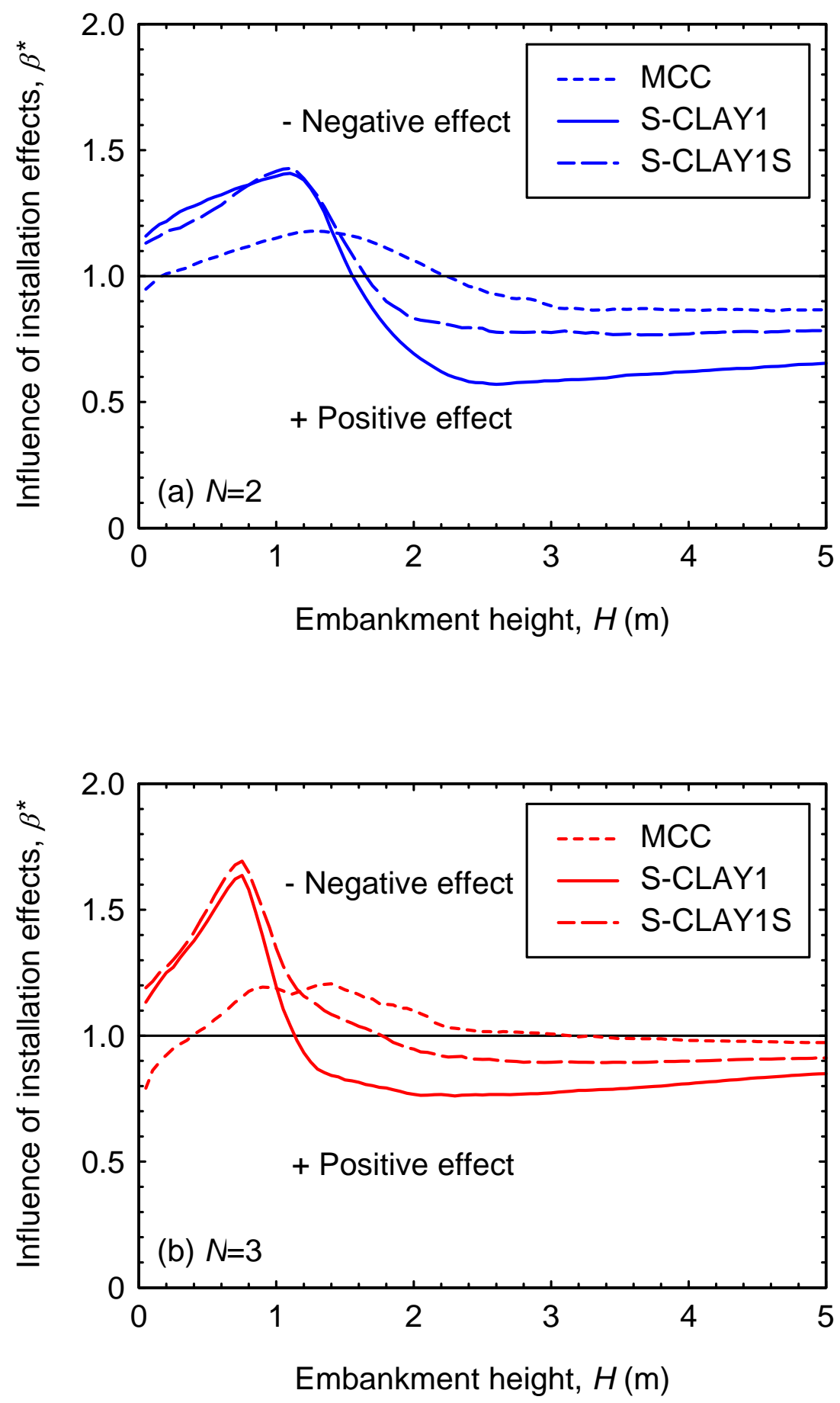


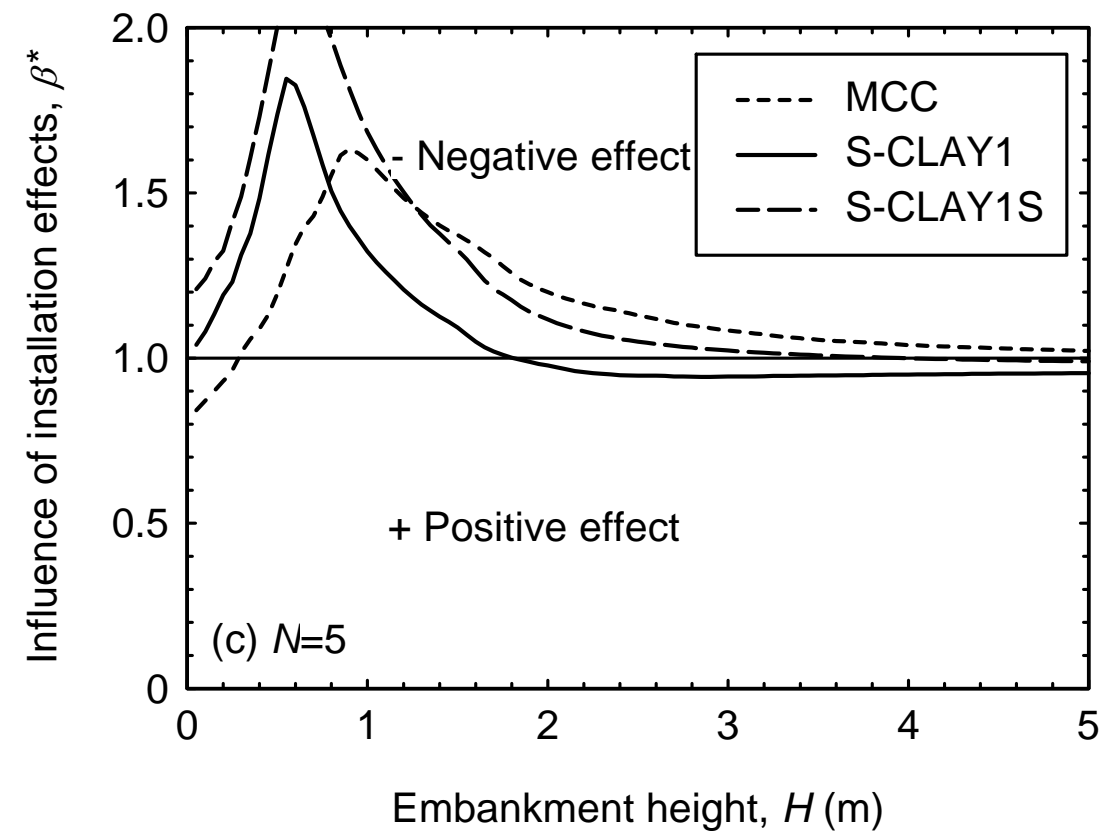

Figure 14. Ratio of the settlement with and without installation effects: (a) $N=2$; (b) $N=3 ;$ (c) $N=5$. 


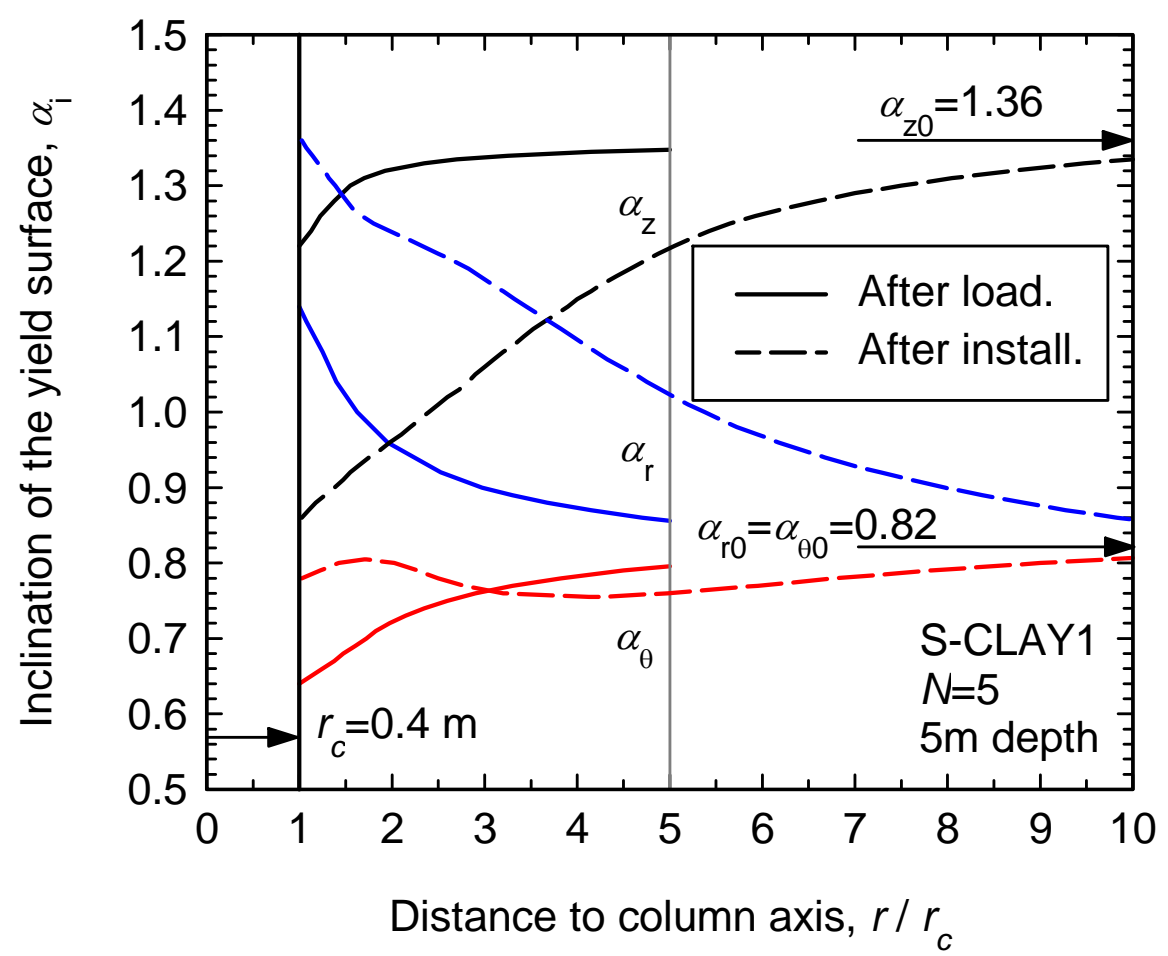

Figure 15. Change in the components of the fabric tensor after embankment loading. 

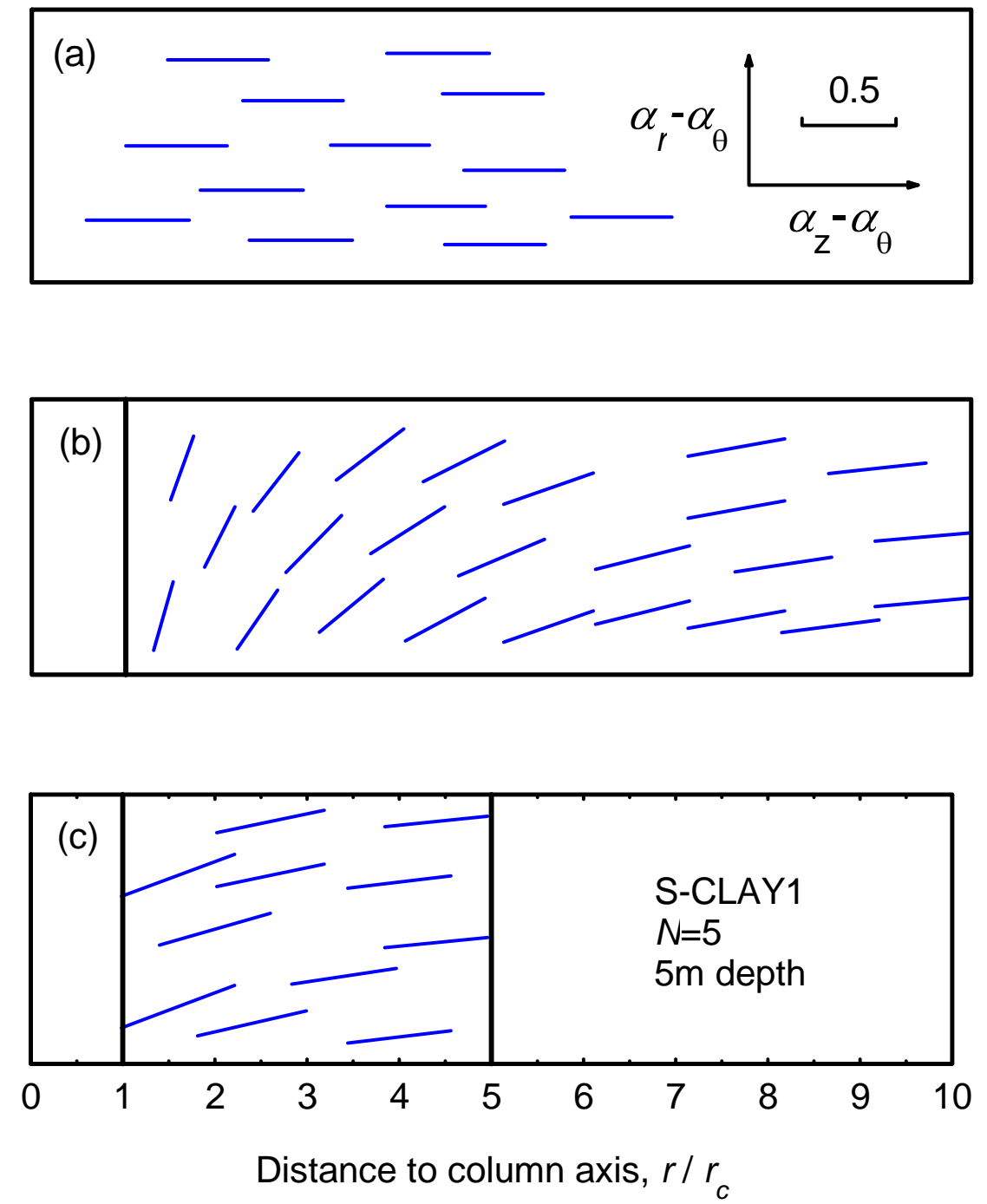

Figure 16. Visualization of the soil fabric: (a) before column installation; (b) after column installation and consolidation; (c) after embankment loading. 